NASA/TM-2005-213860

\title{
Investigations of Shuttle Main Landing Gear Door Environmental Seals
}

Joshua Finkbeiner, Pat Dunlap, and Bruce Steinetz

Glenn Research Center, Cleveland, Ohio

Jeff DeMange

University of Toledo, Toledo, Ohio

Daniel Newswander

Johnson Space Center, Houston, Texas 
Since its founding, NASA has been dedicated to the advancement of aeronautics and space science. The NASA Scientific and Technical Information (STI) Program Office plays a key part in helping NASA maintain this important role.

The NASA STI Program Office is operated by Langley Research Center, the Lead Center for NASA's scientific and technical information. The NASA STI Program Office provides access to the NASA STI Database, the largest collection of aeronautical and space science STI in the world. The Program Office is also NASA's institutional mechanism for disseminating the results of its research and development activities. These results are published by NASA in the NASA STI Report Series, which includes the following report types:

- $\quad$ TECHNICAL PUBLICATION. Reports of completed research or a major significant phase of research that present the results of NASA programs and include extensive data or theoretical analysis. Includes compilations of significant scientific and technical data and information deemed to be of continuing reference value. NASA's counterpart of peerreviewed formal professional papers but has less stringent limitations on manuscript length and extent of graphic presentations.

- TECHNICAL MEMORANDUM. Scientific and technical findings that are preliminary or of specialized interest, e.g., quick release reports, working papers, and bibliographies that contain minimal annotation. Does not contain extensive analysis.

- CONTRACTOR REPORT. Scientific and technical findings by NASA-sponsored contractors and grantees.
- CONFERENCE PUBLICATION. Collected papers from scientific and technical conferences, symposia, seminars, or other meetings sponsored or cosponsored by NASA.

- SPECIAL PUBLICATION. Scientific, technical, or historical information from NASA programs, projects, and missions, often concerned with subjects having substantial public interest.

- TECHNICAL TRANSLATION. Englishlanguage translations of foreign scientific and technical material pertinent to NASA's mission.

Specialized services that complement the STI Program Office's diverse offerings include creating custom thesauri, building customized databases, organizing and publishing research results ... even providing videos.

For more information about the NASA STI Program Office, see the following:

- Access the NASA STI Program Home Page at http://www.sti.nasa.gov

- E-mail your question via the Internet to help@sti.nasa.gov

- Fax your question to the NASA Access Help Desk at 301-621-0134

- Telephone the NASA Access Help Desk at 301-621-0390

- Write to:

NASA Access Help Desk

NASA Center for AeroSpace Information 7121 Standard Drive

Hanover, MD 21076 
NASA/TM-2005-213860

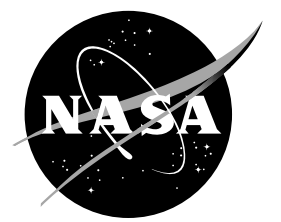

\section{Investigations of Shuttle Main Landing Gear Door Environmental Seals}

Joshua Finkbeiner, Pat Dunlap, and Bruce Steinetz

Glenn Research Center, Cleveland, Ohio

Jeff DeMange

University of Toledo, Toledo, Ohio

Daniel Newswander

Johnson Space Center, Houston, Texas

Prepared for the

41st Joint Propulsion Conference and Exhibit

cosponsored by the AIAA, ASME, SAE, and ASEE

Tucson, Arizona, July 10-13, 2005

National Aeronautics and

Space Administration

Glenn Research Center 


\section{Acknowledgments}

The authors would like to acknowledge Richard Tashiian for his significant contributions involving seal installation and test setup.

Trade names or manufacturers' names are used in this report for identification only. This usage does not constitute an official endorsement, either expressed or implied, by the National Aeronautics and Space Administration.

Available from

NASA Center for Aerospace Information 7121 Standard Drive

Hanover, MD 21076
National Technical Information Service 5285 Port Royal Road Springfield, VA 22100

Available electronically at http:/ /gltrs.grc.nasa.gov 


\title{
Investigations of Shuttle Main Landing Gear Door Environmental Seals
}

\author{
Joshua Finkbeiner, Pat Dunlap, and Bruce Steinetz \\ National Aeronautics and Space Administration \\ Glenn Research Center \\ Cleveland, Ohio 44135 \\ Jeff DeMange \\ University of Toledo \\ Toledo, Ohio 43606 \\ Daniel Newswander \\ National Aeronautics and Space Administration \\ Johnson Space Center \\ Houston, Texas 77058
}

The environmental seals for the main landing gear doors of the Shuttle Orbiters were raised by the Columbia Accident Investigation Board as a potential safety concern. Inspections of seals installed on the Shuttle Discovery revealed that they were permanently deformed and no longer met certified seal compression requirements. Replacement of the seals led to the inability to fully close the main landing gear doors. Johnson Space Center requested that Glenn Research Center conduct tests on the main landing gear door environmental seals to assist in installing the seals in a manner to allow the main landing gear doors to fully close. Further testing was conducted to fill out the seal performance database. Results from the testing indicated that the method of bonding the seals was important in reducing seal loads on the main landing gear doors. Also, the replacement seals installed in Shuttle Discovery were found to have leakage performance sufficient to meet the certification requirements.

\section{Introduction and Background}

During the investigation into the loss of the Shuttle Columbia (STS-107), the Columbia Accident Investigation Board requested an investigation into the Main Landing Gear (MLG) door environmental seals to evaluate their potential contribution to the loss of the Shuttle. The resulting investigation determined that while the seal certification documents specified a minimum compression level to be applied to the seals (after maximum flight deflections had been taken into account), neither the seal installation drawings nor the landing gear rigging drawings specified how to properly rig the MLG doors to achieve the certified seal compression. Furthermore, there was no documentation specifying procedures between flights to ensure continued compliance with the seal certification documentation.

Visual inspections of the MLG door environmental seals on OV-103 (Shuttle Discovery) revealed permanent deformation of varying degree along the length of the seal such that the seal no longer met the certification drawing requirements for minimum height. A clay compression test was performed on the environmental seals and the results indicated gaps larger than the required limits (i.e., too little compression on the seals). These two findings led to a concern that flow could penetrate the MLG bays, resulting in thermal damage to the underlying structure. To alleviate this concern, the flown OV-103 environmental seals (Rev. M) were replaced with new seals (Rev. P) and constant-thickness shims were added to the sealing surface of the MLG bays to satisfy the certified seal compression requirements around the door perimeter. However, the new configuration resulted in higher loads sufficient to prevent the full closure of the MLG doors. Past experience (ca. 1991) with the MLG door rigging mechanism 
demonstrated that similar loads caused structural damage to the mechanism. Therefore, a solution was required on how to install the seals to achieve seal compression requirements without generating excessive loads that could damage the rigging mechanism.

NASA Johnson Space Center (JSC) requested that the NASA Glenn Research Center (GRC) perform a number of engineering evaluations of the MLG environmental seals (both the new design and the old seals removed from $\mathrm{OV}-103)$ to obtain data to guide seal installation and aid in closing the main landing gear doors. In addition, more systematic testing was requested to fill out the seal performance database. A series of exploratory tests were performed on as-received revision P seal specimens to assist in installing the seals so that the MLG doors could be fully closed. These tests evaluated seal performance under various configurations, and the findings from these tests provided NASA Kennedy Space Center (KSC) engineers with data which was valuable in ultimately closing the MLG doors. After the exploratory tests, a systematic series of compression and flow tests were performed on the seals to assist in filling out the seal performance database and evaluating the new revision P seals as replacements for the revision $\mathrm{M}$ seals.

\section{Description of Seal Specimens}

The Thermal Protection System (TPS) of the Space Shuttle Orbiter protects the vehicle and crew from the extreme temperatures of reentry. The TPS contains breaks to allow for opening the landing gear doors and extending the landing gear as shown in figure 1. The MLG doors are highlighted in the photograph. The MLG doors include both a thermal barrier and an environmental pressure seal to prevent hot reentry gases from entering the MLG bay and damaging the interior of the vehicle. Figure 2 depicts a close-up view of one of the MLG doors with its installed environmental seal.

The environmental seal design consists of a bulb seal with an attached tail, both constructed of a silicone rubber (ZZ-R-765, Class IIIa, Grade 50) core overwrapped with Nomex fabric. Small vent holes are punched into the seal material in the front of the seal bulb and are spaced roughly 6 in. apart. These holes allow pressure in the seal bulb to vent to vacuum while the Shuttle is in orbit. The seal was produced by Kirkhill Rubber (Brea, CA) under Northrop Grumman specification number GS179M10. A schematic of the seal design is shown in figure 3 with specific dimensions presented in table 1. The seal certification documents (Rockwell International 05-GS17M10C) assert that the seal leakage may not exceed $3 \mathrm{SCFM} / \mathrm{ft}$ for a differential pressure of $1 \mathrm{psid}$.

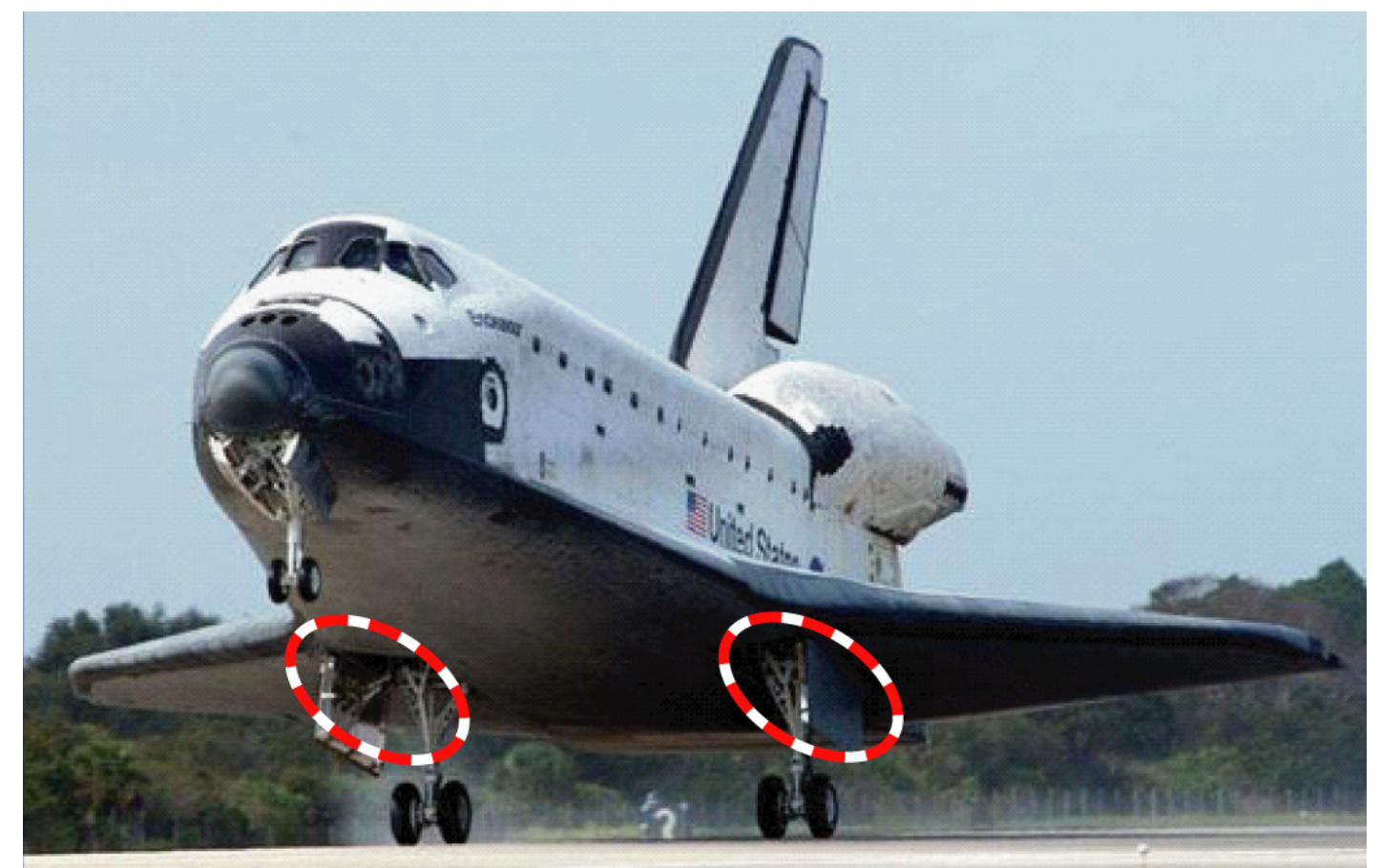

Figure 1.-Photograph of Space Shuttle Orbiter with Main Landing Gear Doors highlighted. 


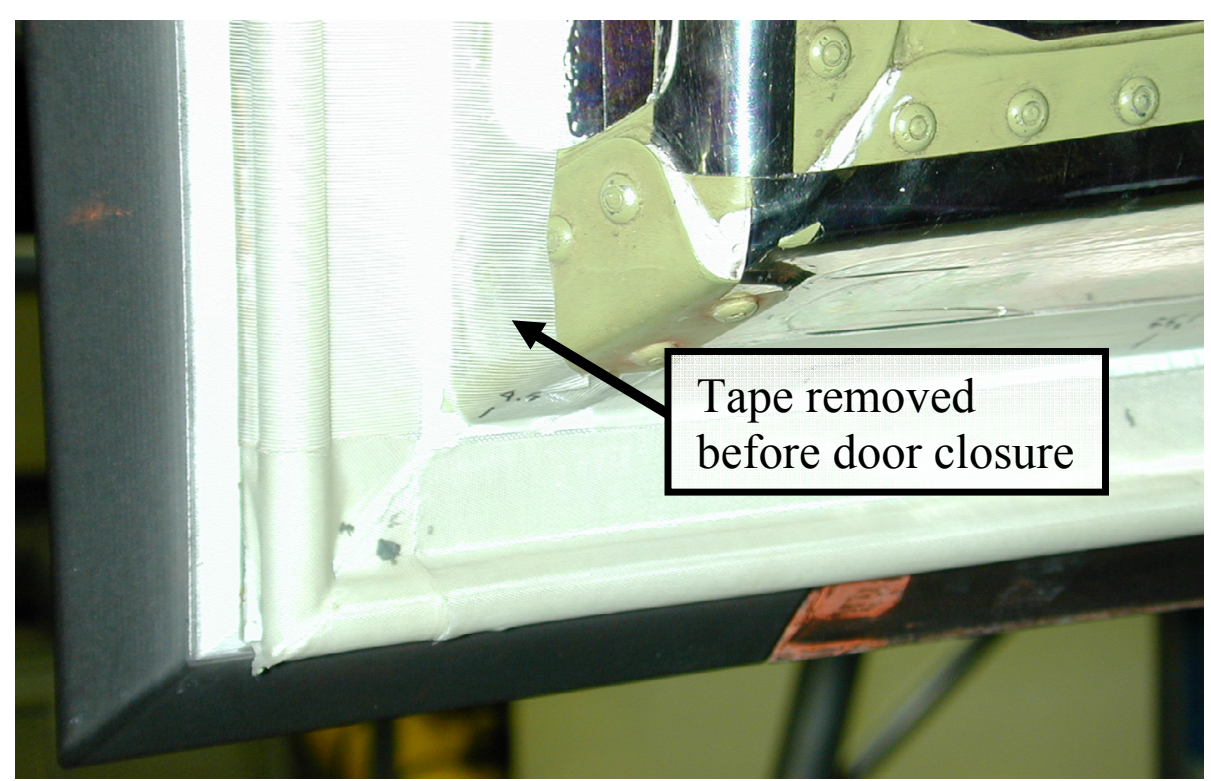

Figure 2.- Photograph of environmental seal installed on Main Landing Gear Door. The tape behind the seal is used for masking and is removed before the door is closed.

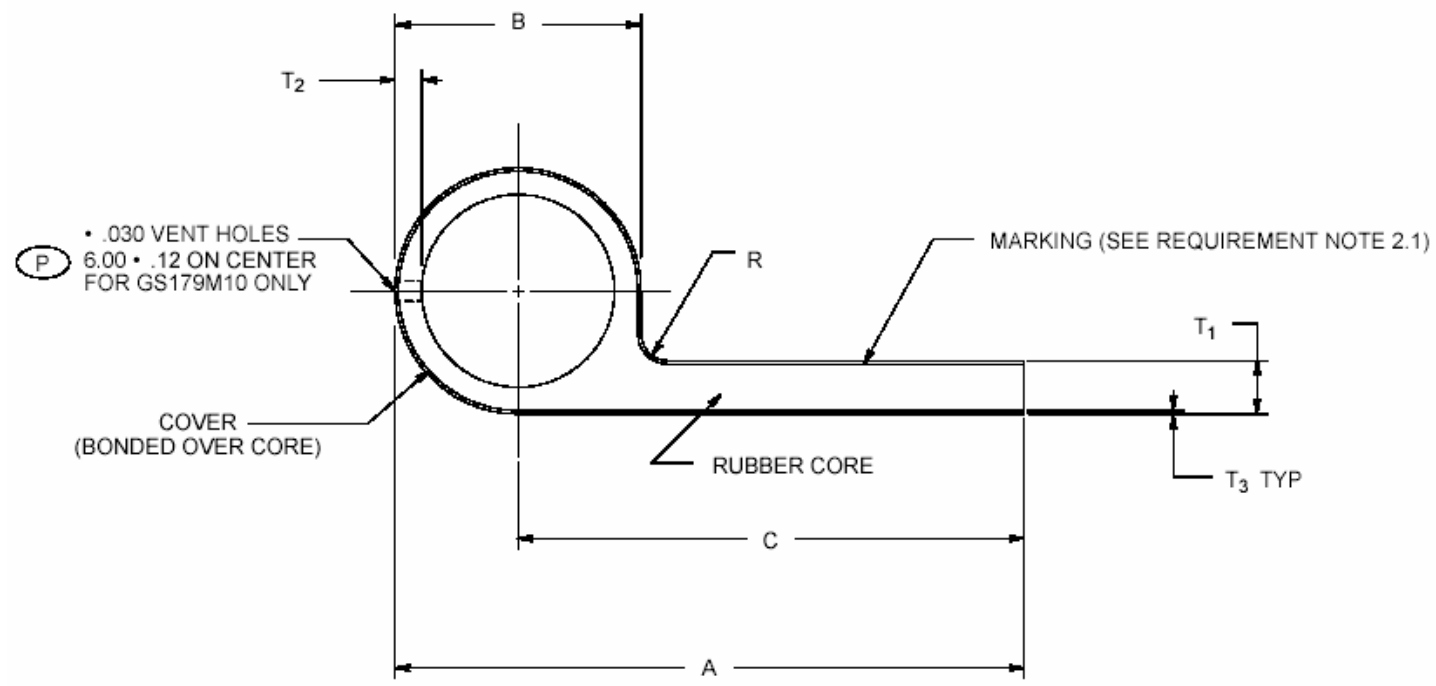

Figure 3.- Schematic of Shuttle MLG door environmental seal (taken from Northrop Grumman Standard GS179M).

TABLE 1.-DIMENSIONS OF SHUTTLE MLG DOOR ENVIRONMENTAL SEAL

[All dimensions are in inches, tolerances are specified as \pm 0.020 in.]

\begin{tabular}{|l|l|}
\hline $\mathrm{A}$ & 1.55 \\
\hline $\mathrm{B}$ & 0.44 \\
\hline $\mathrm{C}$ & ---- \\
\hline $\mathrm{R}$ & 0.12 \\
\hline $\mathrm{T}_{1}$ & 0.08 \\
\hline $\mathrm{T}_{2}$ & 0.06 \\
\hline $\mathrm{T}_{3}$ & 0.010 \\
\hline
\end{tabular}




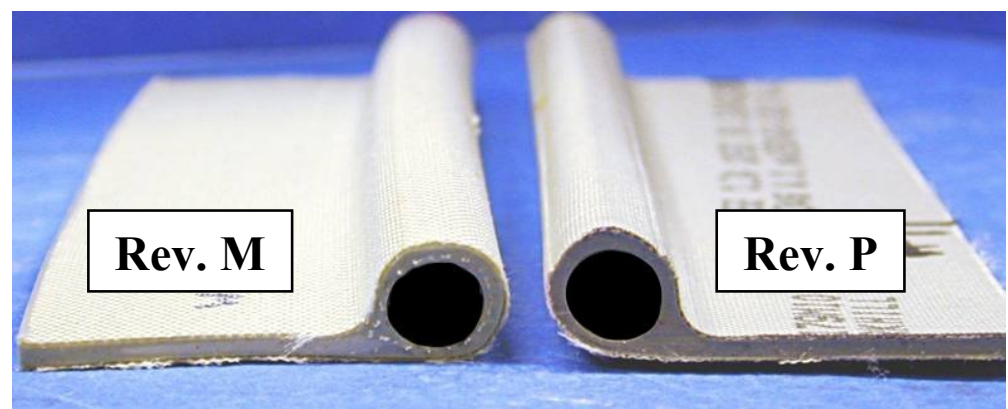

Figure 4.-Photograph comparing as-received Rev. P seal to asreceived Rev. M seal. Note the presence of Nomex fabric impregnation of Rev. M seal bulb.

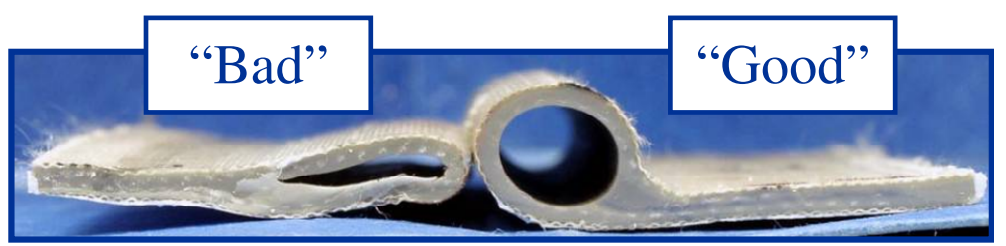

Figure 5.-Photograph of flown Rev. M seals removed from OV-103. Both seals show signs of permanent deformation, with the "bad" specimen showing heavy deformation and the "good" specimen showing light deformation.

Two seal revisions were evaluated in this study and are shown in figure 4 , both in their as-received conditions. The first seal, revision M (Rev. M), featured a Nomex fabric mesh impregnated in the silicone rubber core material. This contrasted with the new revision P (Rev. P) seal, which did not contain the fabric impregnation. Furthermore, the coloration of the rubber material in the Rev. P seal was slightly different than that of the Rev. M seal, indicating a possible difference in the composition of the rubber. The Rev. P seal was noticeably less stiff to the touch than the Rev. M seal.

Several samples of both Rev. M and Rev P. seals were tested in this investigation. Two manufacturing lots of as-received Rev. P seal were evaluated, having lot numbers 024025753450019 (lot -0019) and 024025753450021 (lot -0021). In addition, several Rev. M seals were investigated, including both as-received and flown specimens. The flown seal was removed from the starboard MLG door of OV-103. The bulb of the flown seal had sustained "permanent" deflection which varied in severity along its length. The two extremes of the permanent deformation are shown in figure 5. The "good" seal specimen exhibited approximately 0.035 in. of permanent deformation in the bulb compared to the as-received state, while the "bad" specimen had sustained heavy permanent deformation varying between 0.110 and 0.160 in. with a near-fully collapsed bulb.

A schematic of the flown seal layout is shown in figure 6 . Note that the outboard direction refers to the direction pointing toward the wing tips of the vehicle relative to the door and is synonymous with the hinge line of the door. As shown in the figure, the seal was received in six sections. The forward and aft

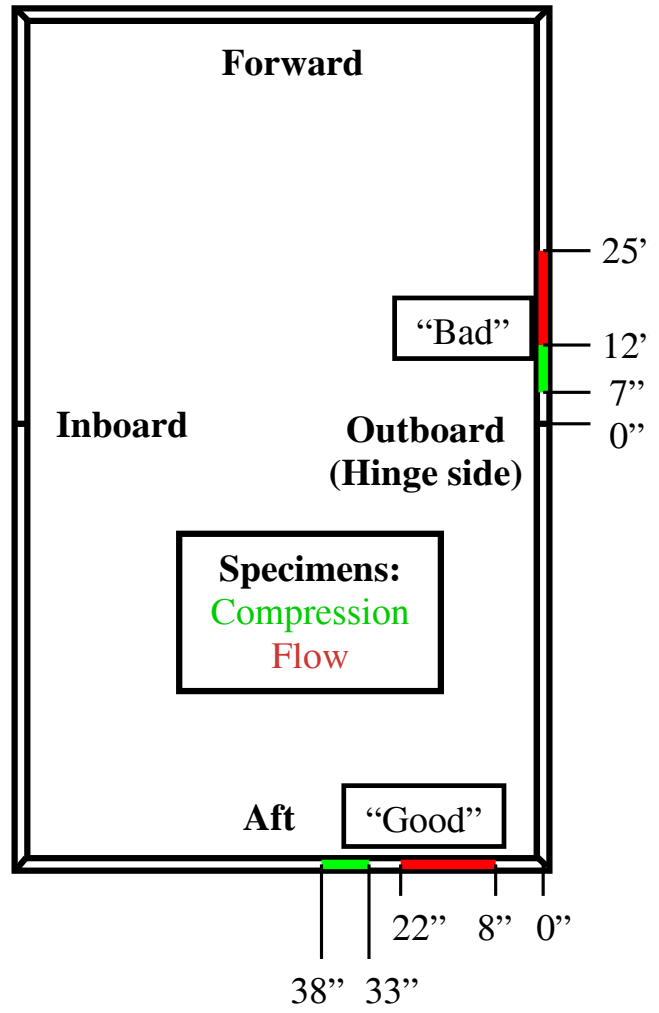

Figure 6.- Schematic of starboard MLG environmental seal removed from OV-103 along with locations of the flow and compression specimens removed from the seal. Locations of the flow specimens are shown in red, and locations of the compression specimens are shown in green. 
sections were each a single length of seal while the inboard and outboard sections were each comprised of two lengths of seal. Also noted in figure 6 are the locations where the flow and compression specimens were removed from the seal. Flow specimens are denoted in red and compression specimens are denoted in green. Where necessary, the seal samples were trimmed to 5 -in. lengths for compression tests and 12 -in. lengths for flow tests.

\section{Experimental Setup}

\section{A. Compression Tests}

1. Test Setup

Room temperature compression tests were performed on samples of the MLG environmental seal to assess load versus compression behavior. The compression rig consists of a servohydraulic load frame, a high-temperature furnace (which was not used), and a laser extensometer (accuracy of \pm 0.00025 in.) and is described in-depth by Dunlap, et al. (ref. 1). Due to the relatively high loading and unloading rates, the laser extensometer could not be used and was monitored only during dwell segments. During the loading and unloading segments, a linear variable displacement transducer (LVDT) (accuracy of $\pm 0.0022 \mathrm{in}$.) was used in place of the laser extensometer. A 500-lb load cell (accuracy of \pm 0.03 percent FS) was used to monitor the load applied to the seal. Samples of the seals were cut to 5 -in. lengths and bonded to aluminum compression test plates according to a JSC-provided procedure which is also used to bond the environmental seal to the MLG door on Shuttle.

Figure 7 depicts a seal compressed between the two loading platens. Prior to insertion of the seal specimens, parallelism of the upper and lower compression platens was adjusted to within $0.001 \mathrm{in}$. After the bonded seal specimens were placed on the stationary lower platen, the movable upper platen was brought into contact with the seal. For these tests, contact was defined using a $0.2 \mathrm{lbf}$ preload applied to the seal. A set of gage pins with \pm 0.0002 -in. accuracy was then used to check the gap size (distance between surface of aluminum mounting plate and contact surface on upper platen), which was nominally measured to be $0.455 \pm 0.006$ in. This corresponded to the bulb diameter of approximately 0.430 in. plus 0.02 in. of room temperature vulcanized silicone rubber (RTV).

\section{Test Procedure}

As shown in table 2, initial exploratory tests were performed on the as-received Rev. P seals to assess the effects of loading rate, mounting plate configuration (groove or no groove), and amount of RTV behind the seal bulb. Figures 8 and 9 depict the different mounting plate configurations and amounts of RTV, respectively. These tests were conducted to better simulate the actual installation conditions of the MLG environmental seals and to provide a roadmap for the systematic tests performed later.

Three types of systematic tests were conducted in the compression rig. Based on the results from the exploratory tests, the first systematic test compressed the seal to 63 percent compression at a loading rate of

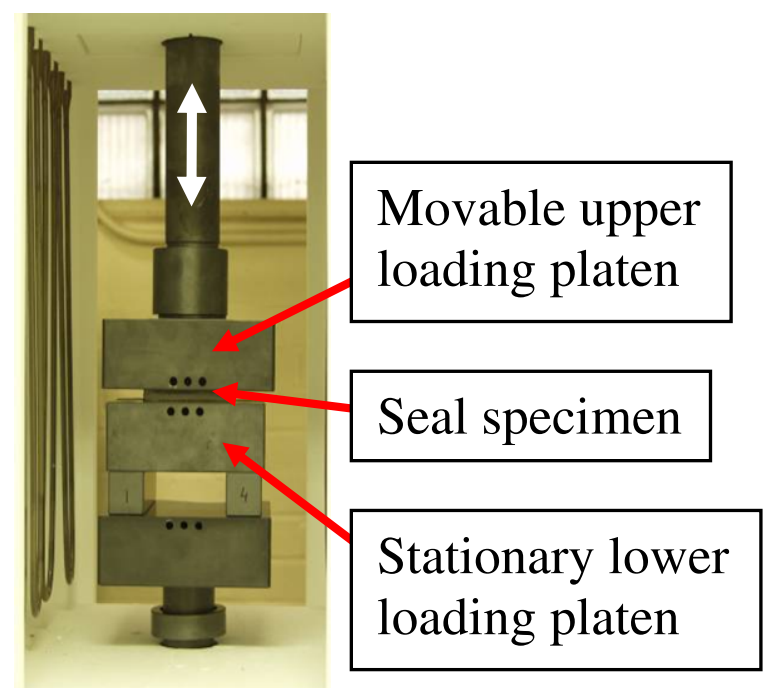

Figure 7.-Photograph of compression specimen in contact with loading platens.

TABLE 2.--EXPLORATORY TEST PARAMETERS

\begin{tabular}{|c|c|c|c|}
\hline $\begin{array}{c}\text { Test } \\
\text { name }\end{array}$ & $\begin{array}{c}\text { Plate } \\
\text { configuration }\end{array}$ & $\begin{array}{c}\text { RTV } \\
\text { amount }\end{array}$ & $\begin{array}{c}\text { Loading rate, } \\
\text { in./sec }\end{array}$ \\
\hline MLG-RTC-P0.1a & $\begin{array}{c}\text { No Groove } \\
\text { MLG-RTC-P0.2a }\end{array}$ & No fillet & 0.002 \\
MLG-RTC-P0.3a & $\downarrow$ & & 0.002 \\
MLG-RTC-P0.4a & & & 0.002 \\
MLG-RTC-P0.5a & $\downarrow$ & $\checkmark$ & 0.200 \\
MLG-RTC-P0.6a & $\downarrow$ & Fillet & 0.200 \\
\hline
\end{tabular}




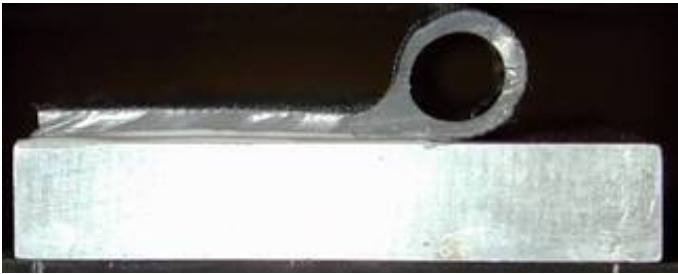

(a)

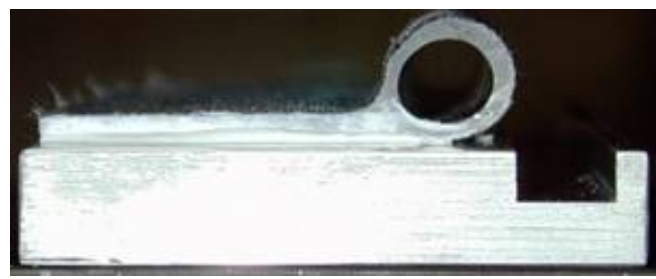

(b)

Figure 8.-Photographs of mounted MLG environmental seal (a) without a groove and (b) with a groove in the aluminum mounting plate.

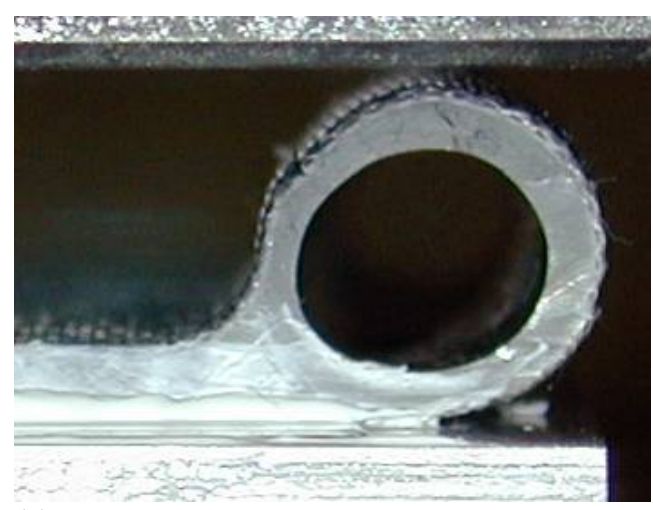

(a)

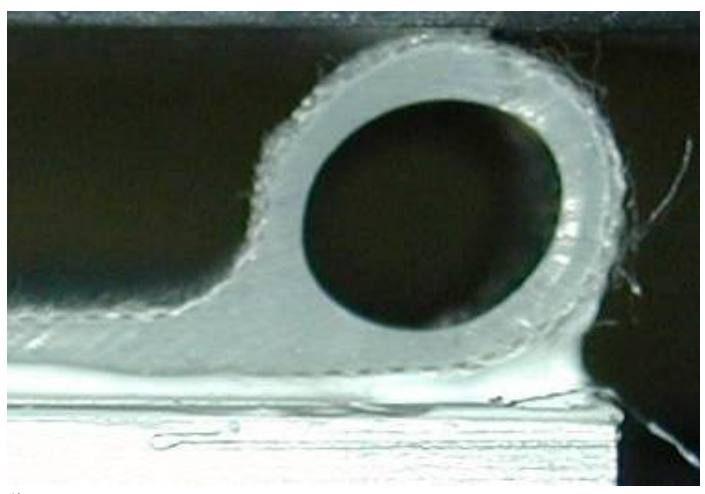

(b)

Figure 9.-Photographs of MLG environmental seal (a) with a clean bond line (i.e., no RTV fillet) (b) and with an RTV fillet behind the seal bulb.

$0.2 \mathrm{in} . / \mathrm{sec}$, held the compression for $1 \mathrm{~min}$, and unloaded the seal. The cycle was then repeated once. The platen displacement and load were recorded during the test.

The second type of test conducted in the compression rig was a $24-\mathrm{hr}$ load decay test. In this test, the seal was compressed to 63 percent of the original bulb diameter. The compression was then held for $24 \mathrm{hr}$ while the displacement and load were recorded.

Finally, a 31-day uninstrumented compression test was conducted by first using a separate fixture. In this test, a 5 in. length of Rev. P seal was compressed to 63 percent compression between two aluminum plates for 31 days. After 31 days, the seal was removed from the fixture and placed in the compression rig, where the load on the seal was measured at several discrete compression levels. The maximum load values at each compression level were then compared to the loads generated in an as-received seal under the same loading conditions.

\section{B. Flow Tests}

\section{Test Setup}

Flow tests were conducted on the MLG environmental seals in order to understand the seal leakage rate as a function of seal construction and permanent deformation, pressure drop across the seal, and compression applied to the seal. Figure 10 shows the assembly of the flow test. The seal specimen was first bonded to a modular test cartridge which included a 0.250 -in.-wide by 0.165 -in.-deep groove adjacent to the seal bulb location to better simulate actual flight setup. The seals were cut and the ends were lightly sanded on a belt sander to achieve a final length of slightly over $12.000( \pm 0.030)$ in. This enhanced sealing of the ends against the aluminum spacer blocks, described below. The seal was bonded to the cartridge using the same procedure as for the assembly of the compression tests. The seal compression level was set by installing appropriately-sized spacer blocks onto the ends of the seal cartridge. RTV (RTV-577 with 3 percent DBTT catalyst) was dabbed onto the cut ends of the seals to minimize end leaks between the seal and the spacer blocks. The spacer blocks were then attached using a thin coat of the same RTV and were bolted down to the cartridge. To permit bonding of the seal ends to the spacer blocks, the seals were compressed using a pair of Plexiglas beams temporarily bolted to the end blocks. The RTV on the spacer blocks was then allowed to cure for $\sim 3$ to $5 \mathrm{hr}$. Faster cure times (e.g., $1.5 \mathrm{hr}$ ) could be achieved by placing the 


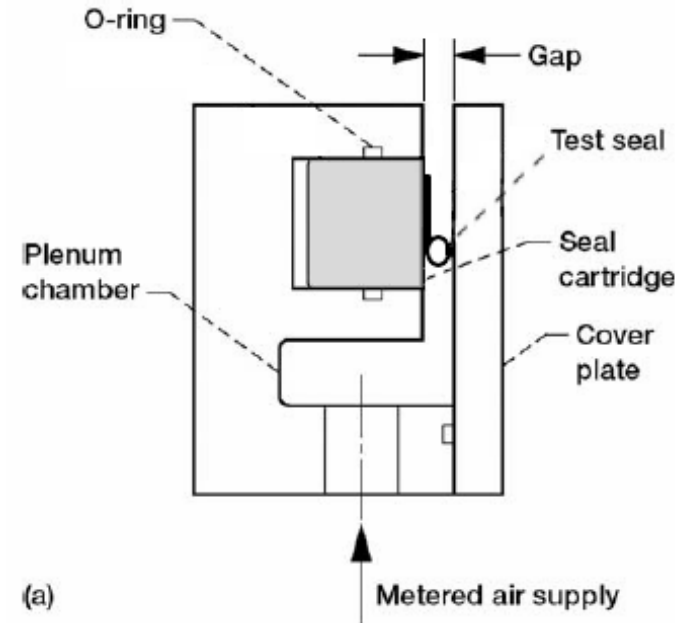

Figure 10.-Assembly of Linear Flow Fixture.

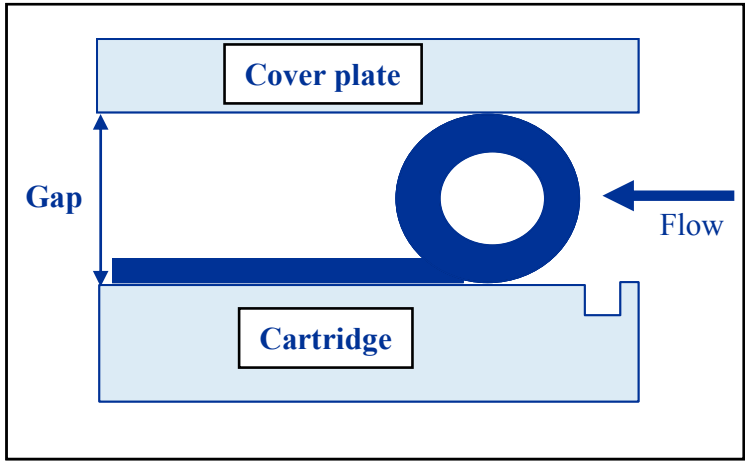

(a)

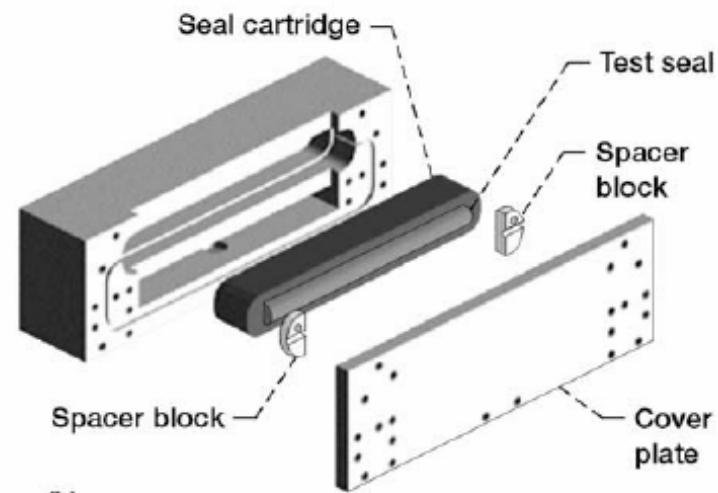

(b)

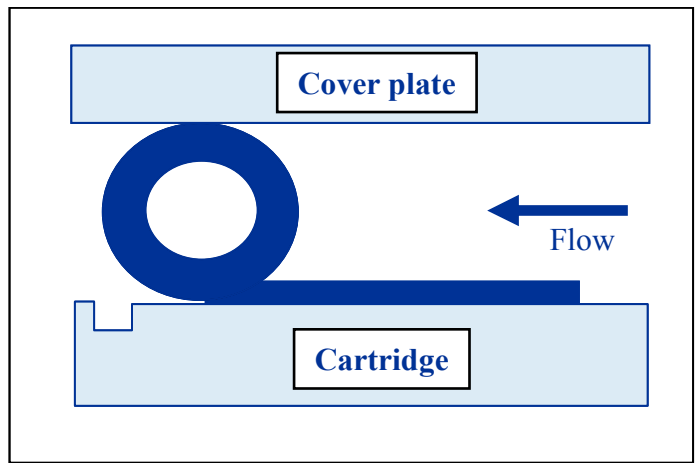

(b)

Figure 11.-Schematic of flow test setup for MLG door seal simulating (a) the bulb-first descent case and (b) the tail-first ascent case for the Shuttle Orbiter.

assembly on a hot plate $\left(\sim 130^{\circ} \mathrm{F}\right)$. Post-installation analysis showed that the seal was well-bonded to the cartridge with an RTV thickness of $\sim 0.020$ in.

Once the spacer blocks had cured, the compression level of the seal was determined. The height of the spacer blocks above the seal mounting surface was measured with a depth gage. From this measurement, the percent compression of the seal could be calculated by

$$
\% \text { Comp }=100 \text { percent } \times \frac{G-g}{D}
$$

where $G$ is the gap size at 0 percent compression, $g$ is the measured gap size of a given test setup, and $D$ is the nominal bulb diameter $(0.430 \mathrm{in}$.). The gap for zero percent compression was estimated by observing when the amount of light passing between the seal bulb and a long bar (supported by appropriately sized gage pins) was minimal.

The cartridge assembly was then installed in the linear flow test fixture as shown in figure 10. An elastomeric o-ring sealed the perimeter of the cartridge (fig. 10 (a)), preventing leakage from passing around and behind the cartridge. A second o-ring sealed below the cover plate and partially through the spacer blocks (fig. 10(b)), ensuring that the primary leakage path was across the test specimen. Small metal-to-metal contacts existed between spacer blocks and the cover plate where the o-ring terminated. This junction was sealed with a small amount of RTV which was allowed to cure before testing commenced. The cover plate was then bolted onto the fixture.

\section{Test Procedure}

Figure 11 shows a cross-section schematic of the test setup. As observed in this figure, the gap setting established the amount of compression. The seals were installed on a flat plate which simulated the actual configuration of the MLG door seal. At each compression level, the seal was tested in two orientations. In the first 
orientation, the seal was pressurized from the bulb side (fig. 11(a)) which simulated the pressurization imposed on the seal during Orbiter descent (i.e., high pressure outside of vehicle). The entire cartridge was then rotated $180^{\circ}$ and pressurized from the tail side (fig. 11(b)) to simulate the Orbiter ascent case (i.e., high pressure in MLG bay).

The data gathered during the tests included the differential pressure across the seal, the flow rate across the seal, and the inlet air temperature to the plenum. The differential pressure across the seal was measured by a Setra model 2395 -psig transducer (accuracy of \pm 0.14 percent FS). Since the tests were performed in ambient conditions, the differential pressure across the seal was measured in psig. A bank of Hastings Model HFM-200 ( \pm 1 percent fullscale) series flow meters were used to measure the flow through the fixture with ranges of 10 SLPM (0.35 SCFM), 100 SLPM (3.5 SCFM), 750 SLPM (26.5 SCFM), and 3000 SLPM (106 SCFM). Only one flow meter was used at any given time. A data point was taken before pressure was applied to the seal in order to determine the zero-offsets of the differential pressure transducer and the flow meter. Then, the pressure was increased in steps of $0.1 \mathrm{psig}$ up to a maximum pressure of $2.0 \mathrm{psig}$. At each pressure step, the pressure and flow rate were allowed to stabilize, after which a data point was recorded. Leakage rates were calculated using a 12 in. seal length. The downstream pressure was ambient room pressure for all tests.

Many tests had sufficiently high flow rates to require switching to different flow meters while the tests were in progress. When a switch to a different flow meter was required, the supply pressure to the fixture was shut off and the fixture was allowed to depressurize. Then, the active flow meter was changed by opening and closing relevant valves. A zero-offset of the new flow meter was recorded, and the test was then allowed to proceed from the last recorded pressure step.

A total of six seal specimens were tested in the flow rig as part of this study and are described in table 3 . Rev. P seals MLG-RTF-P3 and MLG-RTF-P4 were from the same manufacturing lot (lot -0019) while Rev. P seal MLGRTF-P5 was from a separate lot (lot -0021). Table 4 presents the test matrix for the as-received Rev. P seals. Note that the compressed height also includes the 0.02 -in. thickness of the RTV.

\section{TABLE 3.-FLOW TEST IDENTIFICATION AND INFORMATION}

\begin{tabular}{|l|l|l|}
\hline \multicolumn{1}{|c|}{$\begin{array}{c}\text { Seal } \\
\text { identification }\end{array}$} & $\begin{array}{c}\text { Seal } \\
\text { revision }\end{array}$ & \multicolumn{1}{c|}{ Description } \\
\hline MLG-RTF-P3 & Rev. P & Manufacturing lot \#024025753450019 \\
MLG-RTF-P4 & Rev. P & Manufacturing lot \#024025753450019 \\
MLG-RTF-P5 & Rev. P & Manufacturing lot \#024025753450021 \\
MLG-RTF-M1 & Rev. M & "Good" flown seal removed from OV-103 \\
MLG-RTF-M2 & Rev. M & "Bad" flown seal removed from OV-103 \\
MLG-RTF-F1 & Rev. M & As-received seal tested earlier and included for comparison purposes \\
\hline
\end{tabular}

TABLE 4.-GAP SIZE AND ASSOCIATED SEAL COMPRESSION FOR REV. P. THE COMPRESSED HEIGHT INCLUDES THE THICKNESS OF THE RTV BONDING LAYER (0.020 IN.).

\begin{tabular}{|c|c|}
\hline $\begin{array}{c}\text { Compressed height, } \\
\text { in. }\end{array}$ & $\begin{array}{c}\text { Nominal compression, } \\
\text { percent }\end{array}$ \\
\hline 0.452 & 0.0 \\
0.441 & 2.5 \\
0.430 & 5.0 \\
0.410 & 10 \\
0.387 & 15 \\
0.365 & 20 \\
0.345 & 25 \\
0.270 & 42 \\
0.195 & 60 \\
\hline
\end{tabular}




\section{Results}

\section{A. Compression Results}

\section{Exploratory Tests}

Figure 12 presents the first and second loading cycles of the exploratory test on the Rev. P seal test MLG-RTCP0.3a, the case with an included groove, no RTV fillet, and a loading speed of $0.002 \mathrm{in}$./sec. Note that the arrows in the figure indicate the loading and unloading portions of the curve. Five photographs of the seal under compression are displayed in the graph with lines pointing to the reference compression level for each photograph. Of note in the photographs is the buckling-like behavior along the top of the seal bulb. The center of the upper portion of the bulb moved away from the platen at high compression levels, forming a "kidney-like" shape. Figure 12 is representative of the first five exploratory tests listed in table 2, with these five tests demonstrating nearly identical behavior. The increased loading rate and the inclusion of the groove in the aluminum did not affect the load versus compression behavior of the seal.

The sixth test listed in table 2 demonstrated divergence from the other tests and is shown in figure 13 along with photographs of the seal under various levels of compression. The RTV fillet restricted movement of the front wall of the seal, which maintained a more vertical position and did not roll over until the seal had reached a higher compression level than was seen for the other exploratory tests. When the bulb approached a fully collapsed state (e.g.. roughly 55 percent compression), the RTV fillet appears to have restricted the buckling behavior of the top surface of the bulb, and the top of the bulb maintained better contact with the platen than for cases without the RTV fillet. However, the presence of the RTV fillet increased the loads generated by the seal at all compression levels. The largest difference occurred at a compression of 40 percent where the seal with the RTV fillet generated a load three times higher than a seal without a fillet.

Figures 12 and 13 both demonstrate a drop-off in load in the loading portion of the second cycle when compared to the first cycle and show signs of permanent deformation in the seal bulbs. The second loading cycle of figure 12 shows no applied load until roughly 2.5 percent of the original seal bulb diameter. The second loading cycle of figure 13 demonstrates similar behavior until a compression of 5 percent is attained, followed by a larger reduction in second cycle load throughout the remainder of the loading portion of the cycle. Even though the overall loading for the second cycle of the seal with the RTV fillet is lower than the first cycle, the general shape of the loading curve is maintained. This is demonstrated by a slight increase in the slope of the curve at approximately 30 percent compression.

\section{2. $\quad$ Single Compression Tests}

Figure 14 presents the loading portion of the first compression cycle for various seals, including an as-received Rev. M seal, "good" and "bad" flown Rev. M specimens, and a single Rev. P seal. The as-received Rev. M data is plotted twice: first with as-measured data, and second with the curve shifted 0.035 in. to the right (i.e., higher compression), which is equal to the amount of permanent deformation measured in the "good" flown specimen. During compression testing of the "good" flown specimen, the loading platen was not in contact with the seal during the first 0.035 in. of compression because of the permanent deformation of the seal. The shift in the as-received data simulates the effect of an out-of-contact condition for the seal.

Several relationships between the as-received and flown Rev. M seals can be determined from figure 14. First, both flown specimens generated lower loads than the as-received Rev. M specimen, demonstrating a decreasing load with increasing permanent deformation. The "bad" flown seal generated lower loads than the "good" seal, although the "bad" seal had a higher rate of load increase at high compression levels ( $>0.265$ in. compression) than the "good" seal. This sudden increase in load generation from the "bad" seal illustrates the second point from figure 14, which is that the "bad" specimen exhibited a dissimilar loading curve when compared to the other seal specimens. This behavior may have been due to the near-fully collapsed bulb of the "bad" flown specimen. If the "bad" seal bulb closed almost immediately after contact with the test platen, compression of the silicone rubber material would have been the primary loading mechanism instead of compression of the bulb structure, ultimately leading to higher loading rates. Finally, figure 14 illustrates similarity between the as-received data shifted by $0.035 \mathrm{in}$. and the "good" flown seal data. The lightly damaged seal generated loads similar to the as-received seal after the damaged seal was placed under compression. The primary difference between the as-received seal and a lightly damaged seal was the lightly damaged seal's initial lack of contact between the loading platen and the seal bulb due to permanent set.

In addition to the Rev. M seals described above, figure 14 also includes data from an as-received lot -0019 Rev. P specimen. The as-received Rev. P seal had a similar loading curve as the "good" flown Rev. M seal specimen, both of which generated lower loads than the as-received Rev. M specimen. The as-received Rev. M seal generated five times more load than the as-received Rev. P seals at 63 percent compression. The presence of a Nomex fabric 


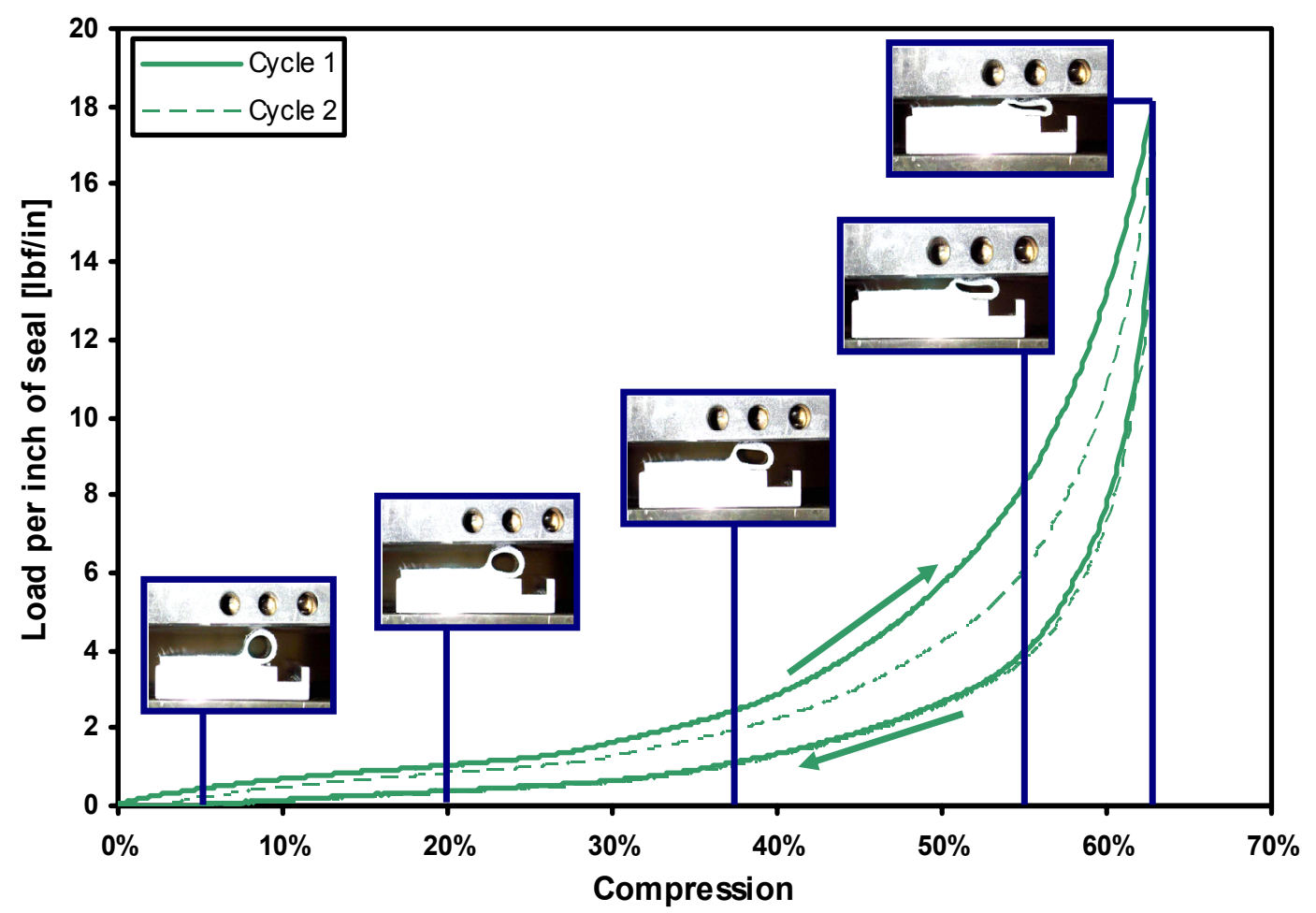

Figure 12.-First two cycles of exploratory load versus compression results of Rev. P seal (Test MLG-RTC-P0.1a): groove in mounting plate, 0.002 in./sec loading speed, no RTV fillet.

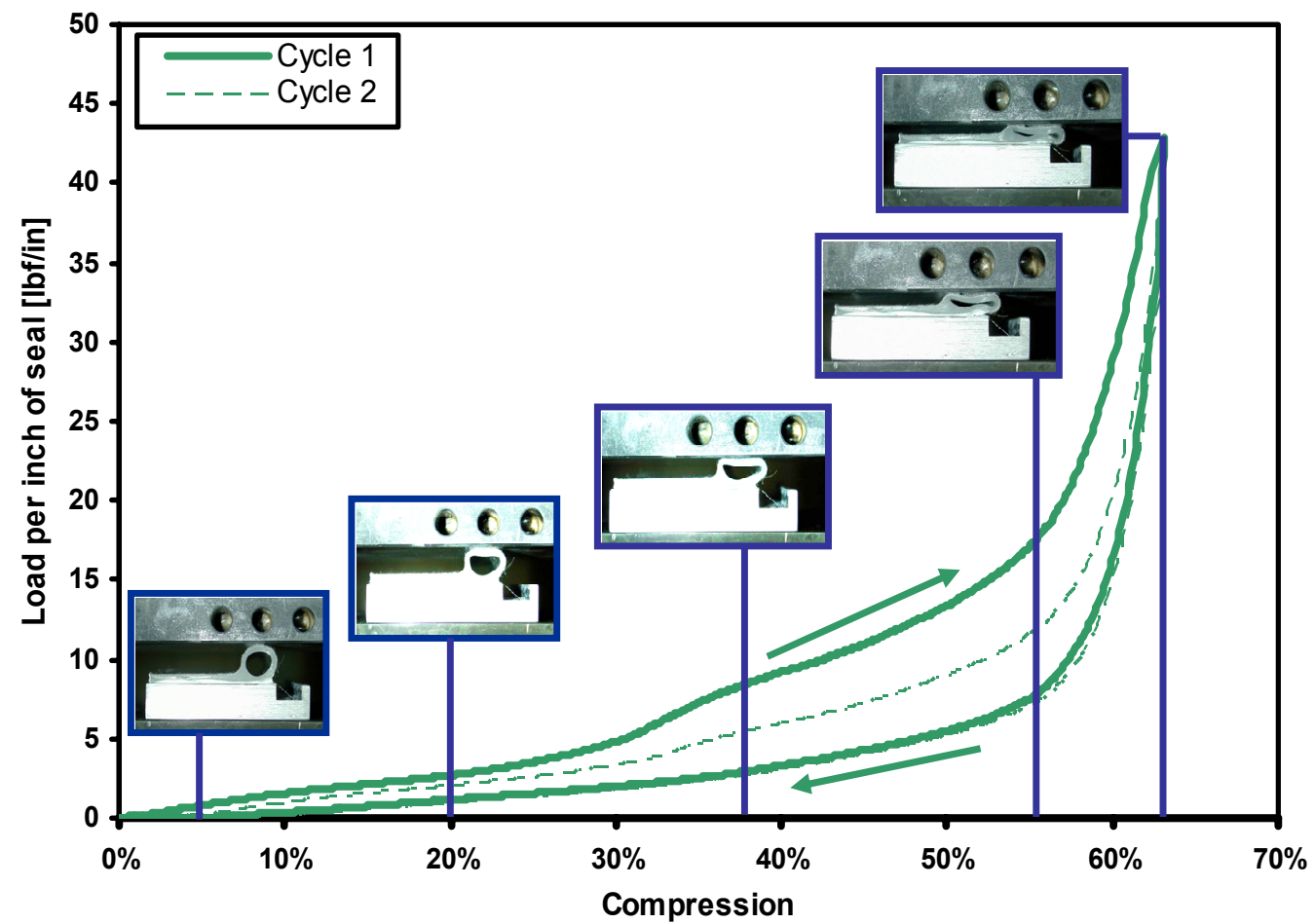

Figure 13.-First two cycles of exploratory load versus compression results of Rev. P seal (Test MLG-RTC-P0.1f): groove in mounting plate, $0.200 \mathrm{in}$./sec loading speed, included RTV fillet. 


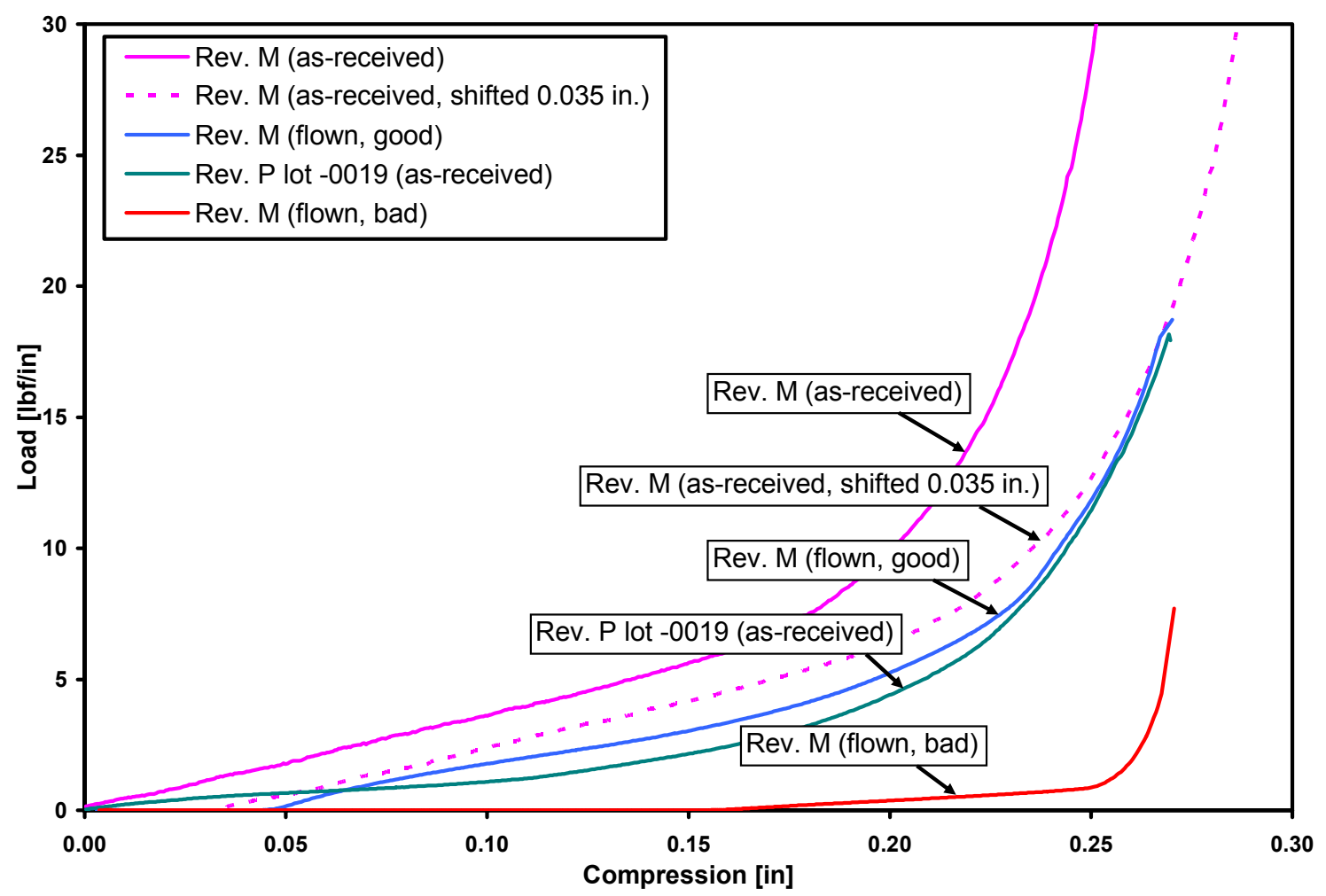

Figure 14.- - Load versus compression data for as-received Rev. M and Rev. P seals as well as flown Rev. $\mathrm{M}$ seals. The as-received Rev. M data is plotted twice: once in an as-measured state, and once with its curve shifted 0.035 in. to the right (i.e., higher compression).

impregnation of the silicone rubber material in the Rev. M seals is the most likely cause for the higher load generation of the Rev. M seal. Based on this data, as-received Rev. P seals can be expected to generate lower loads than as-received Rev. M seals previously used on the Orbiter.

3. 24-hour Test

Figure 15 shows the load versus time plot for 24-hr compression tests of the "good" and "bad" flown Rev. M seals, an average curve of three as-received Rev. P lot -0019 seals, and a curve from a single as-received Rev. P lot -0021 seal. The seals were compressed to a level of 63 percent of the as-received diameter during the duration of the test.

The "good" flown Rev. M seal exhibited the highest loads for the duration of the 24-hr test, followed by the as-received Rev. P seals, and finally by the "bad" flown Rev. M seal. The "bad" flown Rev. M seal exhibited an initial increase in load followed by a drop-off shaped differently than the other seals, which may have been due to drift in the actuator amounting to approximately $0.001 \mathrm{in}$. For the other three seals, the load decreased by $\sim 20$ to 25 percent during the duration of the test. Most of the drop in the load occurred during the first hour, during which the load dropped by roughly 15 to 20 percent.

Of note is the small drop-off in load in the Rev. P lot -0021 seal between 4 and $5 \mathrm{hr}$ into the test. During this time, the temperature in the laboratory dropped slightly, resulting in a thermal contraction of the load train and a subsequent drop in load. The temperature in the lab was brought back to nominal conditions when this drop was recognized and the test proceeded similarly to the other tests (except for the "bad" Rev. M seal).

4. 31-day test

For the 31-day compression test, an as-received Rev. P lot -0019 seal was held at 63 percent compression for 31 days in a static, uninstrumented test fixture. It was then removed from the test fixture and the bulb was measured to be permanently deformed by $\sim 0.050 \mathrm{in}$., which was equivalent to a compression level of 12 percent.

Figure 16 presents a bar chart comparing the peak loads of the first two cycles of an as-received Rev. P seal to the first two loading cycles of the post-31-day test seal for various compression levels. The 31-day test seal generated no load for compressions of 10 percent and lower; this is an expected result because the seal took on approximately 12 percent permanent deformation while it was compressed for 31 days. Upon contact with the platen 


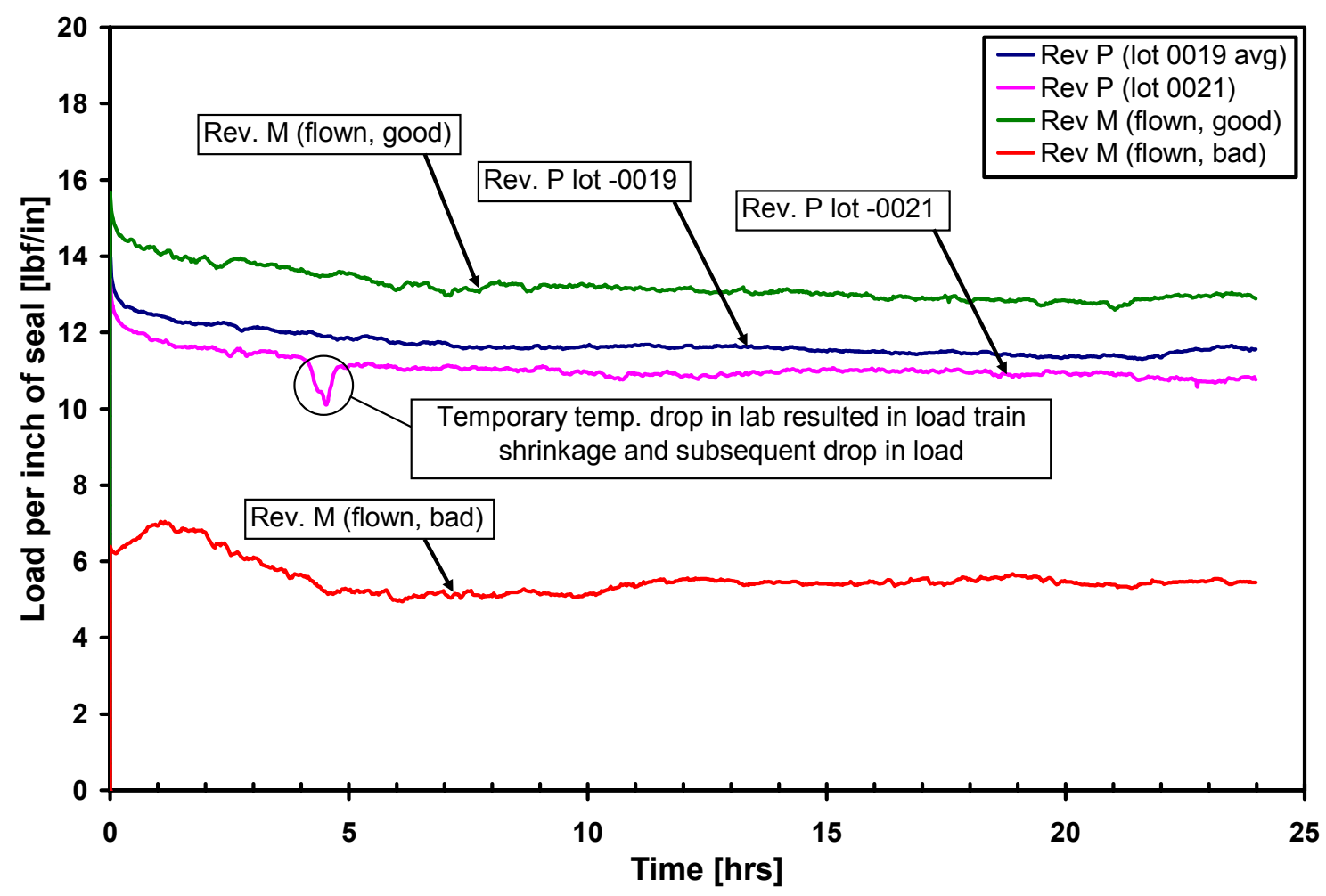

Figure 15.-Load versus time plot of $24 \mathrm{hr}$ compression tests on as-received Rev. P and flown Rev. M seals. The seals were held at 63 percent compression for the duration of the test.

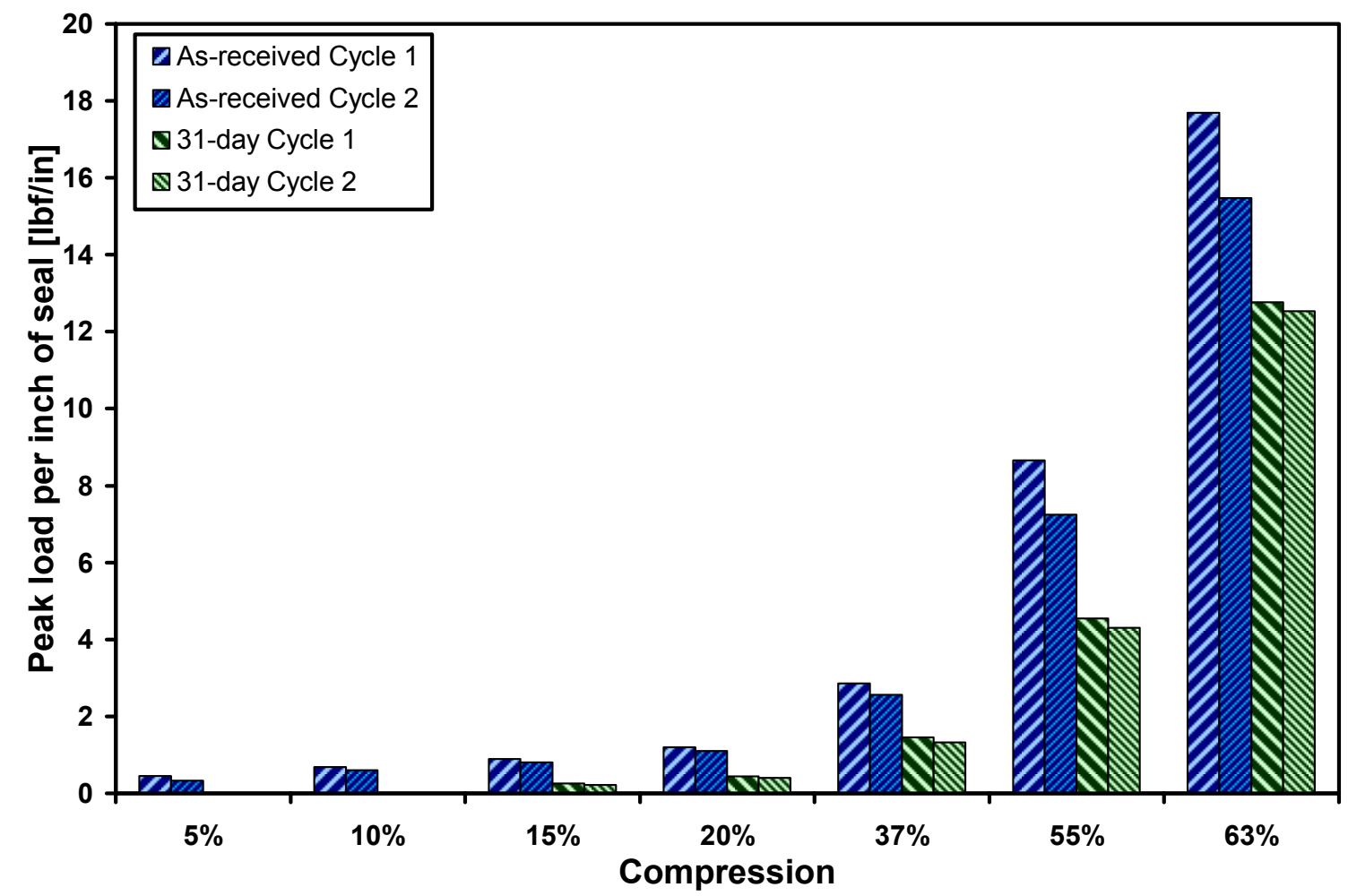

Figure 16.-Peak loads versus compression of first and second incremental loading cycles of as-received and 31-day Rev. P seals. 
and throughout the remainder of the test, the 31-day test seal generated loads lower than those generated by the as-received seal. At the highest compression level of 63 percent, the 31-day test seal generated loads amounting to $\sim 80$ percent of those generated by the as-received specimen.

For all compression levels, the change in load between the two loading cycles was less for the 31-day test seal than for the as-received specimen. This may be due to the permanent set already present in the 31-day specimen. From figure 13, it is known that much of the permanent deformation of a seal occurs during the first hour of compression. Figure 16 appears to indicate that a seal with some permanent deformation takes on additional permanent deformation more slowly than a seal in the as-received state.

\section{B. Flow Results}

Figure 17 presents a sample data set of flow versus pressure differential across the seal from Rev. P seal MLGRTF-P3 in both the bulb-first (i.e., pressurized from the bulb side) and tail-first (i.e., pressurized from the tail side) orientations with a nominal gap size of 0.387 in. and a measured compression of 15.8 percent (nominal compression was 15 percent). The seal in the bulb-first orientation demonstrated a concave-down shape in its flow versus pressure curve, indicating an improvement in seal performance with increasing differential pressure. Conversely, the leakage across the seal in the tail-first orientation was measured to have a concave-up shape with increasing pressure, indicating a reduction in seal performance with increasing differential pressure.

Figure 18 presents flow versus compression data for the three Rev. P seals and an as-received Rev. M seal in the bulb-first orientation at a differential pressure of 1 psig. This pressure was selected because it matches the differential pressure used in the certification documents to specify the maximum seal leakage rate (e.g., $3 \mathrm{SCFM} / \mathrm{ft}$ at 1 psid). Note that the as-received Rev. M seal has fewer data points than the other seals because it was tested before all of the desired compression levels had been defined. A common feature among the Rev. P seals was the plateau or increase in flow rate between 10 and 25 percent compression. The Rev. M curve did not exhibit this plateau or increase in the flow rate and maintained a lower flow rate in this compression region than two of the three Rev. P seals. However, the four seals demonstrated similar leakage responses at high compressions ( $>40$ percent). Regardless of the shapes of the flow curves, the flow across all of the seals was universally below the certified allowable flow rate of $3 \mathrm{SCFM} / \mathrm{ft}$ for a differential pressure of $1 \mathrm{psid}$.

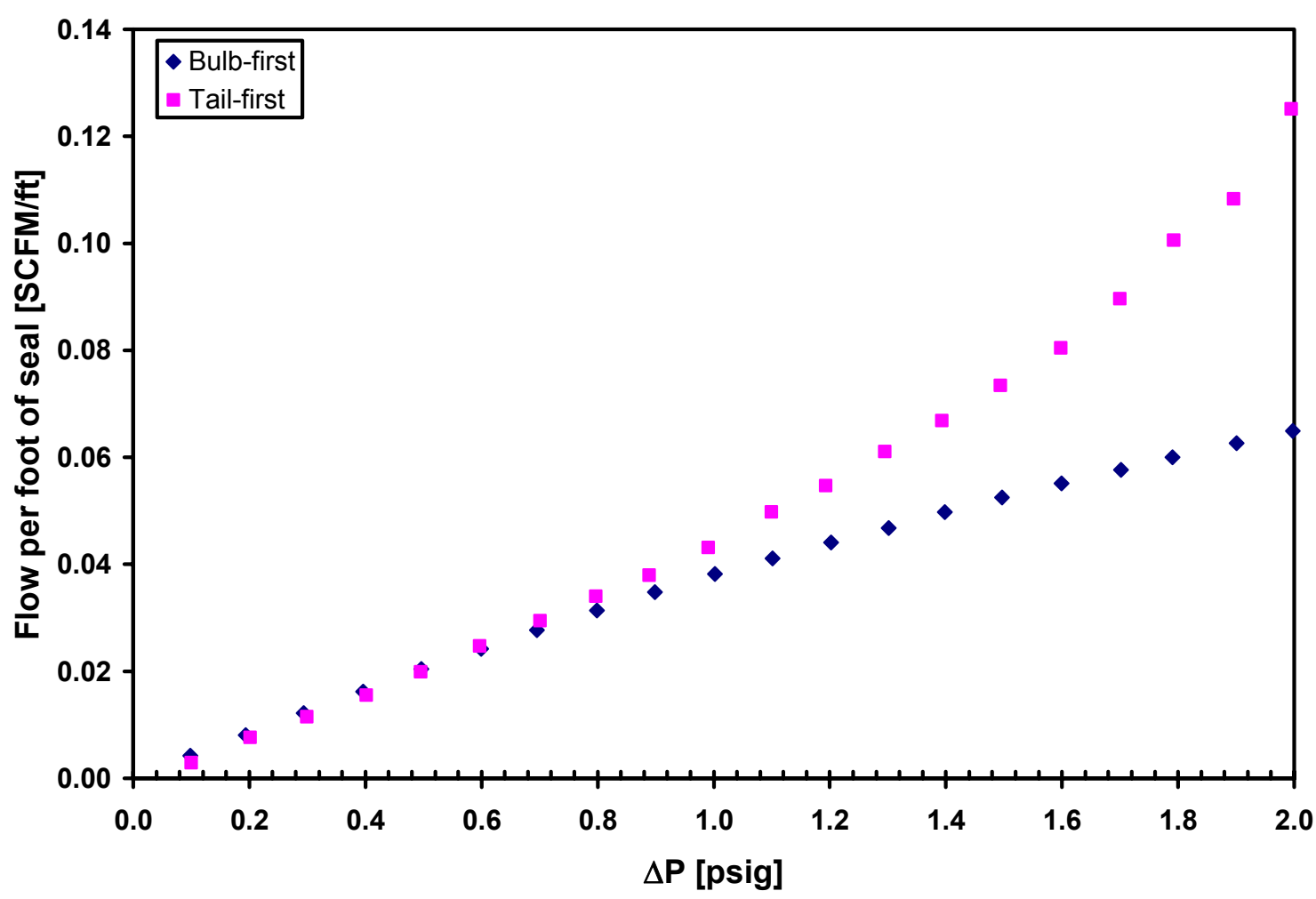

Figure 17.-Flow versus $\Delta \mathrm{P}$ data for Rev. P seal MLG-RTF-P3 at 15.8 percent compression, pressurized from both the bulb side and the tail side. 


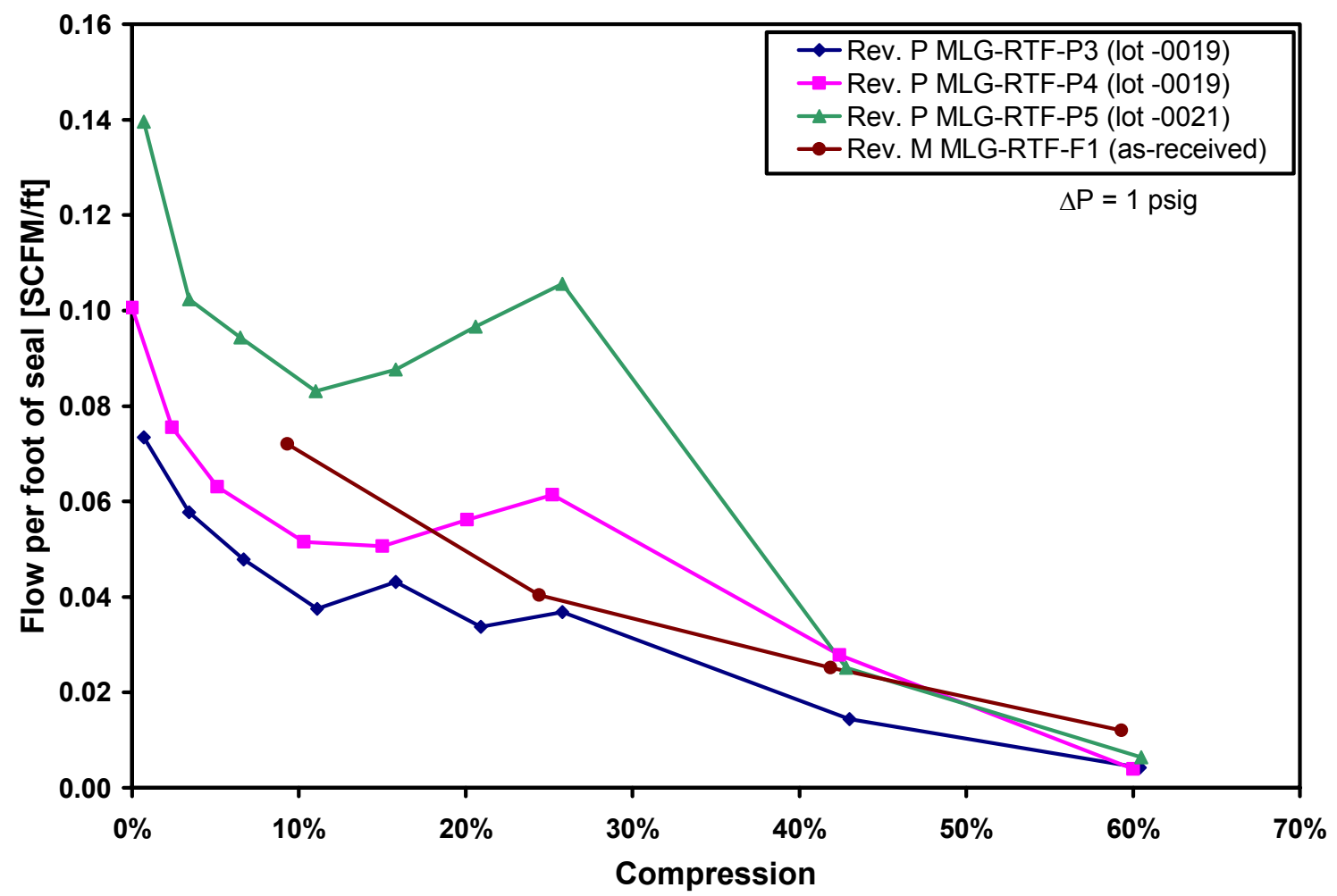

Figure 18.-Flow versus percent compression for the as-received Rev. P seals as well as as-received Rev. M seal at $\Delta \mathrm{P}$ of $1 \mathrm{psig}$ in the bulb-first orientation.

Tail-first flow data from the Rev. P seals at a differential pressure of 1 psig is plotted in figure 19 on a logarithmic scale. Note that the as-received Rev. M seal was tested before tail-first tests were considered, and thus no data is available for this seal. The tail-first flow rates were higher than the bulb-first flow rates (fig. 18) for equal compression levels except for a compression of 60 percent, where seals in the two orientations were measured to have approximately the same flow rate. Seals in the tail-first orientation demonstrated a plateau or small increase in the flow rate between 10 and 25 percent compression, although to a lesser magnitude than the bulb-first cases in figure 18. The Rev. P seals in the tail-first orientation met the certified allowable flow rate ( $3 \mathrm{SCFM} / \mathrm{ft}$ at $1 \mathrm{psid})$ for compressions greater than 2.5 percent.

Figure 20 presents flow results for the "good" flown Rev. M seal as well as an as-received Rev. M seal. The "good" flown seal was tested with a pressure drop of 1 psig in both the bulb-first and tail-first orientations, and the as-received Rev. M flow data is identical to that shown in figure 18. Note that the results are presented in terms of compressed height (i.e., final compressed height of the seal bulb) instead of percent compression. This is because percentage compression is defined in terms of an as-received seal bulb diameter, whereas the flown seals exhibited varying degrees of deformation. The compressed height axis is reversed from the percent compression axis in that a low percent compression equates to a high compressed height. The "good" flown seal in the bulb-first and tail-first orientations produced comparable flow rates except for a compressed height of 0.430 in., where the flow rate across the seal in the tail-first orientation was higher than that for a seal in the bulb-first orientation. In addition, the "good" flown seal had comparable flow performance to the as-received specimen.

Figure 21 presents flow results for the "bad" flown Rev. M seal. The "bad" specimen demonstrated flow rates much higher than the either of the "good" flown seal or the as-received Rev. M seal. The flow rates across the "bad" flown seal were comparable for the two orientations at a compressed height of $0.195 \mathrm{in}$., while the tail-first orientation produced a higher flow rate than the bulb-first orientation at a compressed height of $0.270 \mathrm{in}$. 


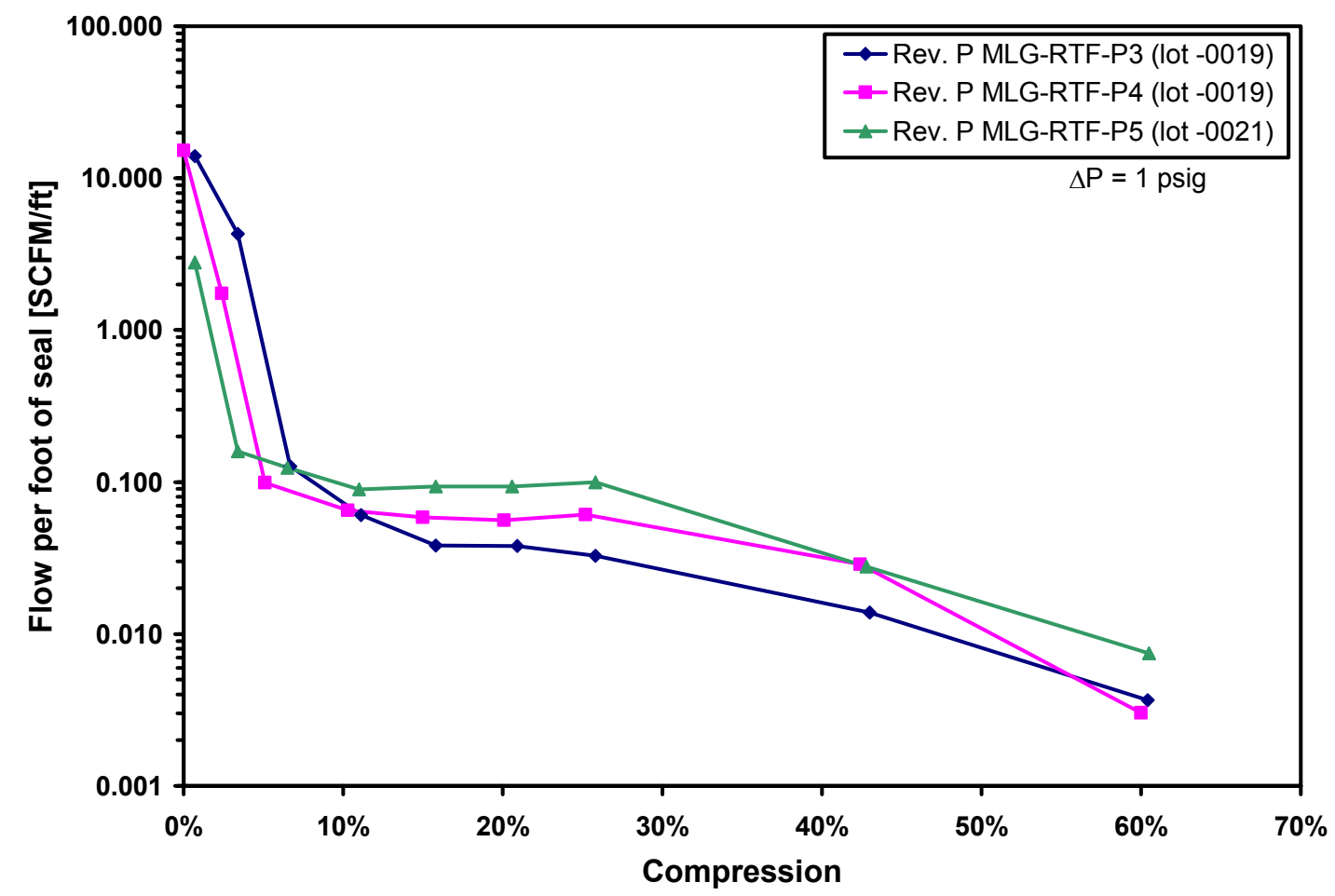

Figure 19.-Flow versus percent compression for as-received Rev. $\mathrm{P}$ seals at $\Delta \mathrm{P}$ of $1 \mathrm{psig}$ in the tail-first orientation. Flow values are plotted on a logarithmic scale.

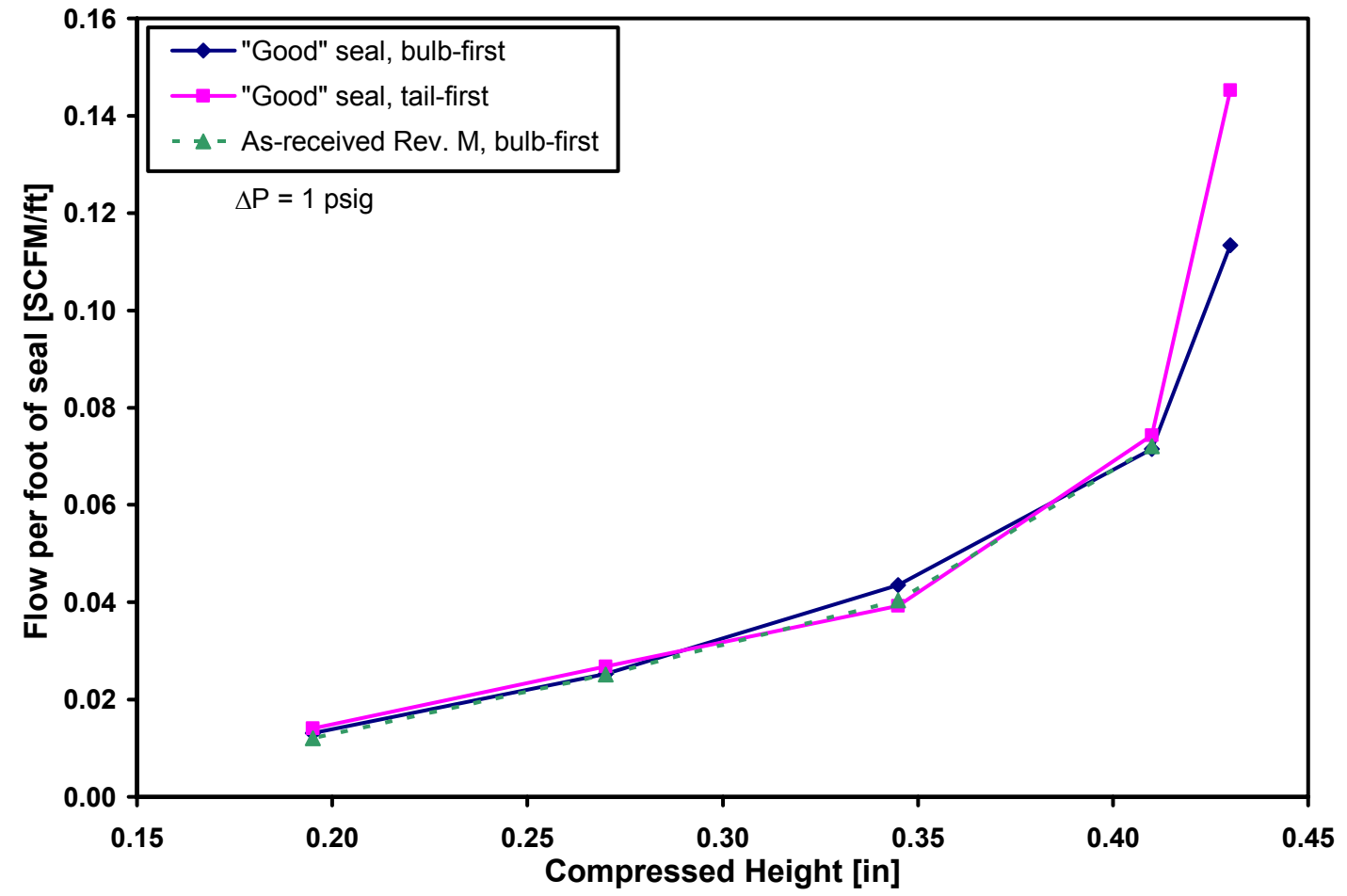

Figure 20.-Flow versus compressed height for "good" flown Rev. M seal (bulb-first and tail-first) as well as as-received Rev. M seal for 1-psig pressure drop. 


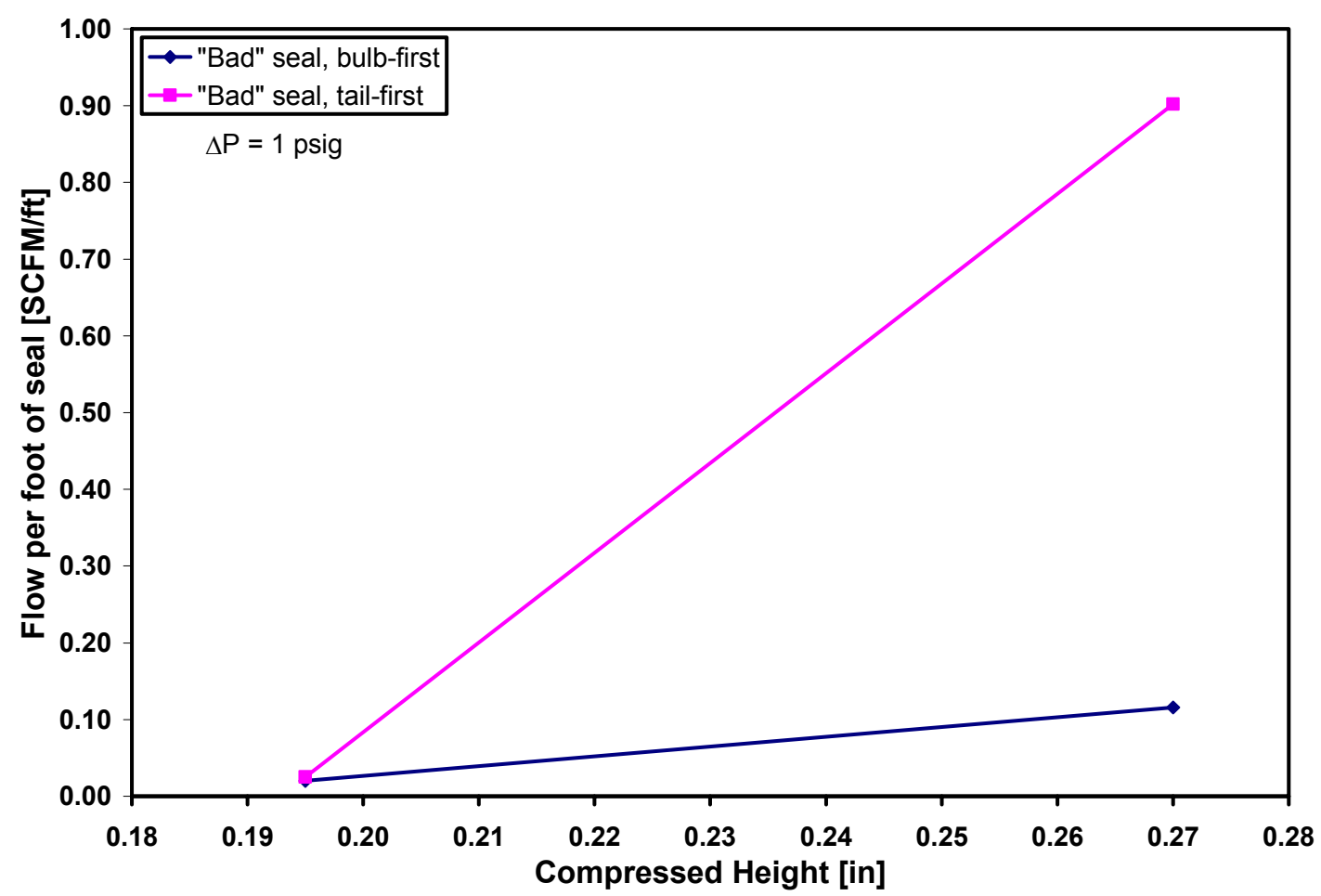

Figure 21.-Flow versus compressed height for "bad" flown Rev. M seal (bulb-first and tail-first) for 1-psig pressure drop.

Flow data could not be measured for the "bad" flown seal at compressed heights greater than 0.270 in. due to an open gap between the seal and the cover plate. For a compressed height of 0.343 in., supply pressures below 0.5 psig generated flows consistent with a small open gap. When the supply pressure was increased above $0.5 \mathrm{psig}$, the seal bulb suddenly inflated and closed the gap. The supply pressure immediately climbed to over 2 psig and was accompanied by a reduction in the flow rate. When the supply pressure was subsequently reduced below $2 \mathrm{psig}$, the seal bulb suddenly deflated and was accompanied by an immediate drop in supply pressure to below 0.5 psig. The pressure drop was followed by an increase in flow rate consistent with a small open gap. Thus, a pressure of 1 psig could not be applied across the seal for a compressed height of 0.343 in. At higher compressed heights, an open gap existed between the seal and the cover plate for all differential pressures with resulting flow rates greater than the capabilities of the flow meters (e.g., >106 SCFM).

\section{Discussion of Seal Bulb Inflation}

As mentioned above, the "bad" flown seal in the bulb-first orientation was observed to exhibit bulb inflation, where the seal bulb expanded to fill an open gap for particular compressed height and pressure combinations. Similarly, other seals in the bulb-first orientation appear to have an increasing sealing effectiveness with increasing pressure, while seals in the tail-first orientation appear to have a decreasing sealing effectiveness with increasing pressure. These effects appear to be related to the same mechanism.

The increase in effectiveness of all Rev. P seals in the bulb-first orientation and the sudden inflation of the "bad" Rev. M seal is hypothesized to be due to the presence of vent holes in the forward side of the seal bulbs. When a seal is oriented bulb-first, the vent holes are located near the stagnation point of the flow. The stagnation pressure inflates the seal because the pressure between the seal and its working surface is less than the internal bulb pressure. This increases the seal footprint against its working surface and enhances the seal's flow blocking capability. Conversely, a tail-first orientation aligns the vent holes away from the high pressure, keeping the internal bulb pressure low (perhaps slightly below ambient) and preventing bulb inflation. If the seal is not sufficiently compressed, the bulb may deflate (and possibly "bend over") and open a gap between the seal and its working surface. This effect is seen in figure 21 for the 1-psig flow result from the "bad" seal specimen at a compressed height of $0.270 \mathrm{in}$. The increase 
in flow rate compared to the other results is likely due to the gap opening up under the loads imposed by the high differential pressure.

Seal bulb pressurization explains several observed patterns in the flow data. The bulb inflation hypothesis predicts that the seal should become more effective at high pressures in a bulb-first orientation and less effective at high pressures in a tail-first orientation. Figure 17 demonstrates concave-down behavior for the bulb-first orientation indicating an improvement in seal performance with increasing pressure, and it demonstrates concave-up behavior for the tail-first orientation which is indicative of decreasing seal performance with increasing pressure. Furthermore, the tail-first flow data in figure 19 at low ( $<10$ percent) compressions demonstrates flow rates orders of magnitude higher than the corresponding bulb-first cases in figure 18, providing experimental verification that the presence of downstream (i.e., on the low pressure side) vent holes play a role in opening the gap between the seal and its working surface. The sudden expansion of the bulb-first "bad" flown Rev. M seal bulb provides a directlyobserved instance of bulb inflation.

\section{Implications for Return to Flight Effort}

As mentioned previously, the investigations of the MLG seals were initiated to assist JSC and KSC engineers in closing the OV-103 MLG doors. After careful inspection of the seals on OV-103 revealed that they had become permanently deformed and no longer met requirements for minimum seal height, the old seals (Rev. M) were removed and new (Rev. P) seals were installed. In an effort to achieve seal compression requirements, constantthickness shims were added to the MLG door sealing surface. However, these changes to the seals generated loads in the MLG door rigging hardware which approached maximum loading limits.

Results from the exploratory compression tests performed at GRC suggested steps to be taken to facilitate the closure of the MLG doors. Seals with an extra fillet of RTV along the bond line below the bulb demonstrated loads up to three times greater than those for seals with a clean bond line (i.e., no RTV fillet), as shown in figures 12 and 13. The presence of the RTV fillet prevented the "rolling over" of the front of the seal bulb material and reduced the magnitude of the buckling behavior observed at the top of the seal bulb.

In response to the GRC exploratory test results, engineers at KSC removed the excess RTV fillet from the bulbs of the newly-installed Rev. P MLG door environmental seals on OV-103. This allowed the closure of the starboardside MLG door, although the port-side door was still unable to fully close. KSC engineers then shortened the door retract link on the door rigging to increase the preload on the retraction mechanism without overloading it. Additionally, custom-height shims were added to seal locations where seal compression levels were measured to be below certified limits. The combination of the removal of RTV, increased preload in the door retract link, and the addition of shims only where the seal compression was below certified limits allowed the closure of the port-side MLG door.

For future flights, seal compression will be monitored between flights to ensure that the seals have not taken on an excessive permanent deformation. Installation procedures for future missions were also amended to include the removal of excess RTV from under the seal bulb.

\section{Conclusions}

1. The presence of an RTV fillet under the seal bulb resulted in increased seal loads compared to a seal without a fillet at the same compression level. Based on this information, KSC engineers removed excess RTV from under the newly installed seal bulbs, which immediately allowed one of the two MLG doors to fully close. Closure of the port-side door was achieved after preload adjustment of the door retract link mechanism.

2. As-received Rev. M seals were up to five times stiffer than the Rev. P seals. This was most likely due to the presence of an impregnated Nomex mesh in the Rev. M seals that was not present in the Rev. P seals.

3. Rev. P seals loaded for $24 \mathrm{hr}$ at 63 percent compression demonstrated a 20 to 25 percent decrease in load compared to the initial peak load. During the first hour of compression, 15 to 20 percent of the initial peak load was lost. A Rev. P seal held at 63 percent compression for 31 days took on 0.050 in. (12 percent) of permanent bulb deformation. Incremental loading tests on this seal revealed that it generated loads 80 percent of those of an undamaged specimen at equal compressions.

4. The new Rev. P seals met the certified seal flow requirements of $3 \mathrm{SCFM} / \mathrm{ft}$ at a differential pressure of $1 \mathrm{psid}$. In the bulb-first orientation (i.e., simulating reentry pressurization), the seal leakage was less than the limiting flow rate for all compressions including cases with 0 percent compression (i.e., very light contact). The tail-first orientation (i.e., simulating Orbiter ascent pressurization) produced leakages below the certified limits for compressions greater than 2.5 percent. 
5. As-received Rev. P seals demonstrated flow blocking characteristics comparable to those measured from tests on as-received Rev. M seals. The primary difference between the two seals was that the Rev. P seals exhibited either a plateau or an increase in the flow rate between 10 and 25 percent compression, while a Rev. M seal did not exhibit this behavior.

6. Seal bulb inflation occurred when the seal was oriented in the bulb-first orientation (i.e., pressurized from the bulb side and simulating reentry pressurization), which improved seal leakage performance. Inflation and subsequent reduction in leakage rate was not observed for seals in the tail-first orientation (i.e., pressurized from the tail side and simulating orbiter ascent pressurization).

\section{Reference}

1. Dunlap, Patrick H. Jr., Steinetz, Bruce M., DeMange, Jeffrey J., and Taylor, Shawn C., "Toward an Improved Hypersonic Engine Seal,” NASA TM-212531, July, 2003. 


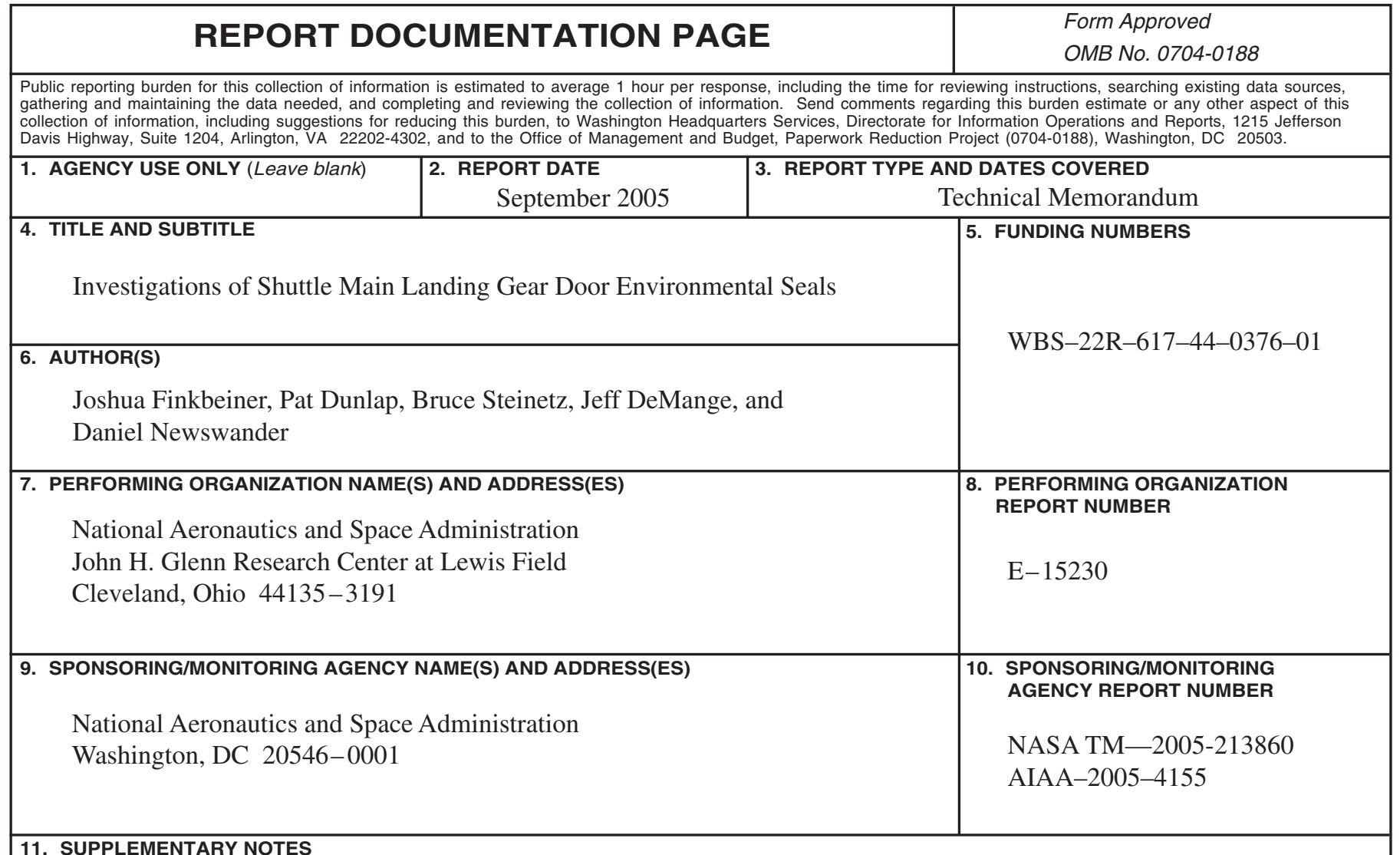

\section{SUPPLEMENTARY NOTES}

Prepared for the 41st Joint Propulsion Conference and Exhibit cosponsored by the AIAA, ASME, SAE, and ASEE, Tucson, Arizona, July 10-13, 2005. Joshua Finkbeiner, Pat Dunlap, and Bruce Steinetz, NASA Glenn Research Center; Jeff DeMange, University of Toledo, 2801 W. Bancroft Street, Toledo, Ohio 43606; and Daniel Newswander, NASA Johnson Space Center. Responsible person, Joshua Finkbeiner, organization code RSM, 216-433-6080.

\begin{tabular}{l|l}
\hline 12a. & DISTRIBUTION/AVAILABILITY STATEMENT \\
Unclassified - Unlimited & 12b. DISTRIBUTION CODE \\
Subject Category: 37 & \\
Available electronically at http://gltrs.grc.nasa.gov & \\
This publication is available from the NASA Center for AeroSpace Information, 301-621-0390. &
\end{tabular}

\section{ABSTRACT (Maximum 200 words)}

The environmental seals for the main landing gear doors of the shuttle orbiters were raised by the Columbia Accident Investigation Board as a potential safety concern. Inspections of seals installed on the Shuttle Discovery revealed that they were permanently deformed and no longer met certified seal compression requirements. Replacement of the seals led to the inability to fully close the main landing gear doors. Johnson Space Center requested that Glenn Research Center conduct tests on the main landing gear door environmental seals to assist in installing the seals in a manner to allow the main landing gear doors to fully close. Further testing was conducted to fill out the seal performance database. Results from the testing indicated that the method of bonding the seals was important in reducing seal loads on the main landing gear doors. Also, the replacement seals installed in Shuttle Discovery were found to have leakage performance sufficient to meet the certification requirements.

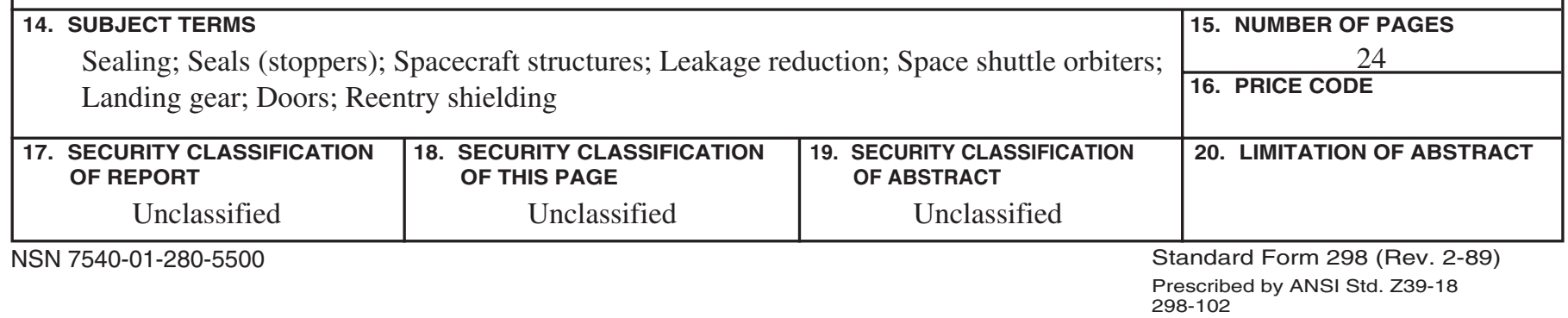



